\title{
Criptógamos do Parque Estadual das Fontes do Ipiranga, São Paulo, SP. Algas, 30: Chlorophyceae (família Scenedesmaceae)
}

\author{
Luciana Rufino Godinho ${ }^{1}$, Augusto A. Comas González ${ }^{2}$ e Carlos Eduardo de Mattos Bicudo ${ }^{1,3}$
}

Recebido: 16.10.2009; aceito: 05.08.2010

\begin{abstract}
Cryptogams of the "Parque Estadual das Fontes do Ipiranga", São Paulo, SP. Algae, 30: Chlorophyceae (família Scenedesmaceae). Taxonomic survey of representatives of family Scenedesmaceae (Chlorophyceae) in the Parque Estadual das Fontes do Ipiranga, São Paulo, Brazil. Twelve genera (Crucigenia, Crucigeniella, Desmodesmus, Didymogenes, Dimorphococcus, Pseudodidymocystis, Pseudotetrastrum, Scenedesmus, Tetrachlorella, Tetrallantos, Tetrastrum and Westella), 47 species and 11 varieties that are not the typical of their respective species were identified. Genus represented by the greatest number of taxa was Desmodesmus, with 16 species and seven varieties that are not typical of their respective species. Followed Scenedesmus with 14 species and four non-typical varieties. Species that occurred in the greatest number of systems were: Desmodesmus communis, D. denticulatus var. linearis, D. intermedius var. acutispinus, Pseudodidymocystis fina, Scenedesmus obliquus var. dimorphus, S. acunae and S. obtusus, that occurred in three localities each.
\end{abstract}

Key words: Brazil, floristic survey, Scenedesmaceae, urban reservoir

RESUMO - (Criptógamos do Parque Estadual das Fontes do Ipiranga, São Paulo, SP. Algas. 30: Chlorophyceae (family Scenedesmaceae). Levantamento florístico dos representantes da família Scenedesmaceae (Chlorophyceae) do Parque Estadual das Fontes do Ipiranga, São Paulo, Brasil. Doze gêneros (Crucigenia, Crucigeniella, Desmodesmus, Didymogenes, Dimorphococcus, Pseudodidymocystis, Pseudotetrastrum, Scenedesmus, Tetrachlorella, Tetrallantos, Tetrastrum e Westella), 47 espécies e 11 variedades que não são as típicas de suas respectivas espécies foram identificadas. O gênero representado pelo maior número de táxons foi Desmodesmus, com 16 espécies e sete variedades que não são as típicas de suas respectivas espécies. Vem a seguir Scenedesmus com 14 espécies e quatro variedades igualmente não típicas. As espécies que ocorreram no maior número de ambientes foram: Desmodesmus communis, $D$. denticulatus var. linearis, $D$. intermedius var. acutispinus, Pseudodidymocystis fina, Scenedesmus obliquus var. dimorphus, S. acunae e S. obtusus, por ocorrerem em três localidades cada uma.

Palavras-chave: Brasil, levantamento florístico, reservatório urbano, Scenedesmaceae

\section{Introdução}

Scenedesmaceae é uma das famílias de Chlorophyceae mais bem representadas no PEFI, Parque Estadual das Fontes do Ipiranga, tanto pela sua presença praticamente ubíqua nos ambientes do Parque quanto pelo número de táxons inventariados.

Leite (1974) é o primeiro trabalho realizado sobre as Scenedesmaceae do PEFI. O trabalho efetua, de fato, o inventário florístico das Chlorococcales do Parque, identificando 60 táxons entre espécies, variedades e formas taxonômicas,
30 dos quais, ou seja, 50\% são de representantes de Scenedesmaceae. Leite (1979) é, até o momento, a maior e a melhor contribuição ao conhecimento da família Scenedesmaceae do Estado de São Paulo. O trabalho incluiu todo o material constante em Leite (1974), porém, aumentou a área de estudo para todo o Estado de São Paulo, listando 118 táxons de níveis infragenéricos de representantes da ordem Chlorococcales, inclusive 56 de Scenedesmaceae. Sant'Anna (1984) é a publicação formal do trabalho de Leite (1979), isto é, da tese de doutorado da mesma autora, então utilizando seu nome de solteira.

1. Instituto de Botânica, Caixa Postal 3005, 01061-970 São Paulo, SP, Brasil

2. Centro de Estudios Ambientales de Cienfuegos, Apartado Postal 202, Cienfuegos 55 100, Cuba

3. Autor para correspondência: e-mail: cbicudo@terra.com.br 
Nesse trabalho, constam 44 espécies representantes da família Scenedesmaceae.

Uma contribuição à ficoflórula planctônica do Lago das Ninféias situado no PEFI foi publicada por Schetty (1998) e a autora descreve e ilustra Scenedesmus acutus Meyen e Desmodesmus protuberans (Fritsch) Hegewald (como Scenedesmus protuberans Fritsch).

Ferragut et al. (2005) publicaram a ficoflórula perifítica e planctônica do Lago do IAG, localizado no PEFI descrevendo e ilustrando 28 táxons de níveis infragenéricos de Scenedesmaceae.

Os cinco trabalhos acima incluem chaves para identificação dos gêneros, espécies, variedades e formas taxonômicas identificados, além de descrições abrangentes e ilustração.

Em Sant'Anna et al.(1989) constam sucintamente descritos e ilustrados 41 táxons de Scenedesmaceae identificados de materiais do fitoplâncton do Lago das Garças e o estudo é dominantemente taxonômico, porém, também abrange aspectos ecológicos.

Bicudo \& Bicudo (1967) citaram Scenedesmus acuminatus (Lagerheim) R. Chodat f. maximus Uherkovich, S. acuminatus (Lagerheim) R. Chodat var. tortuosus (Skuja) Uherkovich e S. brasiliensis Bohlin em trabalho que explica a composição florística e a gênese de comunidades flutuantes de algas no Lago das Ninféias situado no Jardim Botânico de São Paulo.

Bicudo et al. (1999) abordaram a dinâmica das populações fitoplanctônicas de um ambiente eutrofizado, fornecendo uma lista bem extensa de espécies, no entanto, como o anterior, sem incluir descrições nem ilustrações que possibilitem reidentificação.

Diversos autores desenvolveram trabalhos ecológicos no Parque Estadual das Fontes do Ipiranga trabalhando com o fitoplâncton ou o perifíton de determinados ambientes do Parque. Assim, Moura (1996), Ramírez (1996), Gentil (2000), Vercellino (2001), Crossetti (2002), Tucci (2002), Barcelos (2003), Fonseca (2005) e Fermino (2006) efetuaram suas pesquisas no Lago das Garças, um ambiente eutrófico; Lopes (1999) e Vercellino (2001) no Lago do IAG, um ambiente oligotrófico; e Biesemeyer (2005) e Fonseca (2005) no Lago das Ninféias, um ambiente oligo-mesotrófico. Na maioria desses trabalhos, os nomes dos materiais identificados constam apenas de listas, sem descrição e/ou ilustração. Apenas os de Moura (1996) e de Tucci (2002) apresentaram ilustrações de algumas espécies de Scenedesmaceae.
O presente trabalho pretendeu dar a conhecer os gêneros, as espécies e as variedades taxonômicas dos representantes de Scenedesmaceae que ocorrem na área do Parque Estadual das Fontes do Ipiranga utilizando, para tanto, todo o material coletado ou documentado em publicações.

\section{Material e métodos}

Os métodos para coleta, preservação e estudo do material utilizados neste trabalho constam em Bicudo $\&$ Menezes (2006).

Visando sua mais pronta localização, gêneros, espécies e variedades taxonômicas foram atualmente relacionados em ordem alfabética crescente, sendo as formas dentro de suas respectivas variedades, estas dentro de suas espécies e as últimas dentro dos gêneros competentes. Espécies, variedades e formas taxonômicas que constam da literatura, mas que não foram reencontradas durante o presente levantamento, tiveram seus nomes citados nas chaves de identificação e no texto precedidos por um asterisco.

O sistema de classificação adotado foi o de Bourrelly (1990), por ser o único que inclui todos os gêneros até então conhecidos, os quais foram classificados segundo critérios uniformemente aplicados a todo o universo dos gêneros nele incluídos.

Todas as amostras, seja de perifiton seja de fitoplâncton, encontram-se depositadas no Herbário Científico do Estado "Maria Eneyda P. Kauffmann Fidalgo" (SP) do Instituto de Botânica da Secretaria do Meio Ambiente do Estado de São Paulo.

Conforme Ferragut et al. (2005) para fins de distribuição no PEFI foram considerados todos os trabalhos taxonômicos e ecológicos. O sistema utilizado para classificação da família foi van-denHoek et al. (1997) e para os níveis específicos foi utilizado Komárek \& Fott (1983).

\section{Resultados e Discussão}

Os 12 gêneros presentemente identificados para o PEFI têm a seguinte situação sistemática:

\author{
Chlorophyceae \\ Chlorococcales \\ Scenedesmaceae \\ Crucigenia \\ Crucigeniella
}


Desmodesmus

Didymogenes

Dimorphococcus

Pseudodidymocystis

Pseudotetrastrum

Scenedesmus

Tetrachlorella

Tetrallantos

Tetrastrum

Westella

\section{Crucigenia Morren}

Cenóbios planos constituídos por quatro células que flutuam livremente no ambiente. A forma do cenóbio varia entre quase circular, quadrado, retangular e rômbico. As células podem ser elipsoidais, triangulares trapezoidais ou ter a forma de um quarto de círculo e distribuem-se ao redor de um pequeno espaço central quadrado. É comum ocorrerem cenóbios múltiplos. Cenóbios filhos formam um ângulo de $45^{\circ}$ em relação ao cenóbio materno. Cloroplasto lateral, em forma de lâmina com pirenóide (Bicudo \& Menezes 2006).

\section{Chave para as espécies de Crucigenia}

1. Cenóbios com margens externas das células mais ou menos retas ou levemente côncavas

C. tetrapedia

1. Cenóbios com margens externas das células convexas

2. Parede celular lisa C. quadrata

2. Parede celular ornamentada, com espessamento semelhante a verruga C. mucronata

Crucigenia mucronata (G.M. Smith) Komárek, Archiv für Protistenkunde 116: 25, fig. 31. 1974.

Figura 1

Cenóbios planos, quadrangulares, espaço quadrangular no centro, formados por 4 células; células ovais a trapeziformes, parede celular com 1 espessamento semelhante a verruga nos ângulos, onde as células se contactam, margem externa convexa ou levemente côncava, 4,5-8,3 × 2,0-6,4 $\mu \mathrm{m}$; cloroplastidio parietal, 1 pirenóide.

Hábitat: plâncton no Lago do IAG (SP399779) e no Lago das Garças (SP399781, SP399782); primeira citação da ocorrência da espécie no Lago do IAG e no Lago das Garças.

Crucigenia mucronata (G.M. Smith) Komárek lembra morfologicamente Crucigeniella pulchra
(West \& West) Komárek, no entanto diferem pelos cenóbios em forma quadrática de Crucigenia mucronata (G.M. Smith) Komárek, e mais alongada com as células projetadas em relação ao eixo longitudinal. Segundo Komárek (1974), Crucigenia fenestrata (Schmidle) Schmidle var. tetraverruca Hortobágyi talvez seja uma variedade taxonômica de Crucigenia mucronata (G.M. Smith) Komárek.

Crucigenia quadrata Morren, Annales des Sciences Naturelles 20: 415, pl. 15, fig. 1-5. 1830.

Figura 2

Cenóbios planos, irregularmente poliédricoarredondados a irregularmente ovais, espaço quadrangular no centro, formados por 4 células; células elípticas a trapezoidais, margens externas marcadamente convexas, 6,0-9,3 × 3,2-3,9 $\mu \mathrm{m}$; cloroplastidio parietal, 1 pirenóide.

Hábitat: plâncton no Lago das Garças (Sant'Anna et al. 1989: 95, fig. 63).

Ahlstrom \& Tiffany (1934) consideraram $C$. quadrata Morren var. octogona Schmidle sinônimo heterotípico de Tetrastrum alpinum Schmidle. Crucigenia quadrata Morren var. octogona Schmidle f. pulchra Hortobágyi possui cenóbio formado por quatro células muito similares àquelas da variedadetipo de C. quadrata Morren. Conforme Komárek (1974), o holótipo em Hortobágyi (1967) apresenta modo de reprodução idêntico ao de representantes de Tetrastrum tornando, por isso, necessário considerar C. quadrata Morren var. octogona Schmidle f. pulchra Hortobágyi uma variedade de Tetrastrum triangulare (R. Chodat) Komárek ou uma espécie independente.

Crucigenia tetrapedia (Kirchner) West \& West, Transactions of the Royal Irish Academy: série B, 32: 62.1902.

Figuras 3-4

Cenóbios planos, mais ou menos quadrados, sem espaço central, formados por 4 células; células triangulares, margens externas retas ou levemente côncavas, 2,2-5,0 $\times$ 1,9-4,3 $\mu \mathrm{m}$; cloroplastidio parietal, sem pirenóide.

Hábitat: plâncton no Lago do IAG (SP399779; Ferragut et al. 2005: 152, fig. 73) e no Lago das Garças (Sant'Anna et al. 1989: 95, fig. 58; Gentil 2000: 52, fig. 4).

Conforme Sant'Anna et al. (1989) e Silva (1999), os espécimes que estudaram apresentaram as mesmas características da ilustração original em West \& West 
(1902); no entanto, a ilustração em Ferragut et al. (2005) apresenta um espaçamento muito pequeno entre as células, o que mostra ser esta característica variável dentro da espécie. Na verdade, segundo Komárek (1974), não existe uma abertura no centro do cenóbio, mas somente um pequeno espaçamento em forma de cruz formado pela junção das paredes celulares das células do cenóbio.

\section{Crucigeniella Lemmermann}

Cenóbios formados por quatro células planas, de vida livre, não envoltos por restos da parede celular da célula-mãe. Os cenóbios são quadrados a pouco retangulares e podem juntar-se formando cenóbios múltiplos. As células podem ser desde elipsoidais ou reniformes até levemente assimétricas tanto em relação ao plano equatorial quanto ao lateral; e os pólos são amplamente arredondados ou assimetricamente acuminados. Na porção central da colônia existe um espaço losangular. Reprodução geralmente por 4 autósporos orientados no mesmo sentido do cenóbio materno; podem formar sincenóbios transitórios. Cloroplastídio parietal, lateral, com um pirenóide (Bicudo \& Menezes 2006).

\section{Chave para as espécies de Crucigeniella}

1. Cenóbios com as margens externas das células quase retas ou levemente côncavas

C. crucifera

1. Cenóbios com as margens externas das células convexas

2. Células com pirenóide ................... C. apiculata

2. Células sem pirenóide C. rectangularis

Crucigeniella apiculata (Lemmermann) Komárek, Archiv für Protistenkunde 116: 38, fig. 67-69. 1974.

Figura 5

Cenóbios planos, espaço quadrado no centro, formados por 4-16 células, sincenóbios até 64 ou mais células; células ovais, assimétricas, zona de união entre células ocupando metade do comprimento celular, parte de contato entre células assimetricamente aguda, truncada, proveniente de espessamento da parede celular, margens externas das células mais ou menos convexas, extremidades celulares formando ângulo agudo, 4,2-5,8 × 2,5-2,9 $\mu \mathrm{m}$; cloroplastidio parietal, 1 pirenóide.

Hábitat: plâncton no Lago das Garças (SP399782); primeira citação da ocorrência da espécie.
As células podem apresentar um espessamento na parede celular, mas, segundo Comas (1996), tais engrossamentos apicais da parede celular não são tão evidentes nos espécimes cubanos quanto nos da Europa Central, fato que ocorreu com os atuais espécimes do PEFI, por não apresentarem espessamento da parede celular.

Crucigeniella crucifera (Wolle) Komárek, Archiv für Protistenkunde 116: 39, fig. 78-81. 1974. Figura 6

Cenóbios planos, aproximadamente hexagonais, espaço losangular a quadrático no centro, formados por 4-16 células; células oblongas irregulares quase reniformes, margem externa da célula quase reta ou levemente côncava, 3,1-9,2 × 2,3-4,5 $\mu \mathrm{m}$; cloroplasto parietal, 1 pirenóide; parede celular sem espessamento.

Hábitat: plâncton no Lago das Garças (Sant'Anna et al. 1989: 95, fig. 61-64; Gentil 2000: 53, fig. 5).

Bicudo et al. (1992) observaram unicamente exemplares jovens, que se distinguem dos adultos quanto à forma mais reniforme das células e ao plano de divisão dos autósporos em relação ao cenóbio maternal. Os mesmos autores mencionaram que tais morfotipos eram coincidentes com certos estágios do desenvolvimento de Crucigeniella crucifera (Wolle) Komárek, conforme ilustrações em Komárek (1974: fig. 78, 81). Concordamos com Bicudo et al. (1992), apesar dos presentes espécimes apresentarem células com formas um tanto irregulares, porém oblongas.

Crucigeniella rectangularis (Nägeli) Komárek, Archiv für Protistenkunde 116: 37, fig. 65-66. 1974.

Figura 7

Cenóbios planos, abertura quadrática irregular no centro, formados por 4-16 células; células ovais assimétricas, células externas levemente convexas, células unidas delicadamente por mucilagem comum, 4,0-8,0 $\times$ 2,5-5,0 $\mu \mathrm{m}$; parede celular lisa, sem espessamentos; pirenóide às vezes não muito visível. Hábitat: plâncton no Lago das Garças (Sant'Anna et al. 1989: 95, fig. 62) e no Lago do IAG (Ferragut et al. 2005: 152, fig. 74).

O material ilustrado por Komárek (1974: fig. 102) possui cenóbio com a abertura central rombóide, não possui pirenóide e as células situamse irregularmente (comparar com Willea). Segundo Komárek (1983), C. rectangularis (Nägeli) Komárek foi descrita de modo a permitir várias interpretações. 
As características diagnósticas da espécie são: (1) células ovóides ou ovais, (2) espessamento polar distal em cada célula, (3) abertura central no cenóbio e (4) número irregular de autósporos (também ocorrem cenóbios constituídos por duas células, como em Willea). Picelli-Vicentim (1987) mencionou que $C$. rectangularis (Nägeli) Komárek assemelha a Crucigenia quadrata Morren, porém, a última possui cenóbios sempre quadrados, enquanto que em C. rectangularis (Nägeli) Komárek eles são retangulares, isto é, nitidamente alongados em uma direção.

\section{Didymogenes Schmidle}

Cenóbios planos, formados por duas células individuais ou 4-8-16 células, não é comum células solitárias, não possuem mucilagem. As células do cenóbio não se desenvolvem firmemente juntas, elas estão próximas, mais ou menos num nível acima, numa posição paralela. As células são semi-lunadas, a parede celular pode ser lisa ou verrucosa, sem espinhos ou com espinhos terminais. Reprodução por autósporos.

Chave para identificação das espécies de Didymogenes

1. Células externas com espinhos D. anomala

1. Células externas sem espinhos D. palatina

* Didymogenes anomala (G.M. Smith) Hindák, Biológia 29: 565. 1974 三 Tetrastrum anomalum G.M. Smith, Transactions of the American Microscopical Society 45: 187, pl. 15, fig. 21-27. 1926.

Figura 8

Cenóbios planos, dispostos linearmente, formados por 2-4 células; células cilíndricoarqueadas, semi-lunadas, pólos arredondados, algo truncados, células externas com espinhos grandes, de comprimento aproximadamente igual ao da célula, unidas aos pares pelos lados convexos, 5,0-11,0 × 2,0$3,1 \mu \mathrm{m}, 1-2$ espinhos polares, retos, divergentes, 4,010,0 $\mu \mathrm{m}$ compr.; cloroplastidio parietal, 1 pirenóide. Hábitat: plâncton no Lago das Garças (Sant'Anna et al. 1989: 95, fig. 60).

Didymogenes anomala (G.M. Smith) Hindák possui espinhos presentes, caracter que diferencia esta espécie de D. palatina Schmidle que não apresenta espinhos. Os espécimes estudados em Sant'Anna et al. (1989) apresentaram medidas pouco menores do que em Komárek \& Fott (1983: 6,0-17,8 × 1,2-5,0 $\mu \mathrm{m})$.
* Didymogenes palatina Schmidle, Hedwigia 45: 35, fig. 1-4. 1905.

Figura 9

Cenóbios planos, dispostos linearmente, formados por 4 células; células cilíndrico-arqueadas, semi-lunadas, unidas aos pares pelos lados convexos, pólos arredondados, espinhos ausentes, 7,0-12,0 $\times$ 2,0-3,0 $\mu \mathrm{m}$; cloroplastidio parietal, 1 pirenóide.

Hábitat: plâncton no Lago das Garças (Sant'Anna et al. 1989: 95, fig. 57).

Didymogenes palatina Schmidle é, morfologicamente, distinta de D. anomala (G.M. Smith) Hindák pela ausência de espinhos em seus cenóbios. Sabe-se, entretanto, que pode ocorrer perda ou ganho de espinhos em células mais velhas e que esse fato pode gerar confusão, principalmente, no presente caso em que as espécies não apresentam outras características diferenciais. Hindák (1974) mencionou o fato de terem sido observadas células com espinhos no lago Zamecky e células com e sem espinhos no rio Danúbio (Hindák 1974: pl. 2, fig. 5-7, pl. 3, fig. 5). O referido autor sugeriu, sem jamais concretizar sua sugestão, a necessidade de preparar culturas unialgais para provar que a ausência de espinhos é um caracter permanente e, consequentemente, bom para distinguir as duas espécies em pauta.

\section{Tetrachlorella Koršikov}

Cenóbios formados por quatro células dispostas num único plano e envoltas por mucilagem. As células são elipsoidais e distribuem-se em dois pares cujos eixos longitudinais são paralelos entre si. As células internas unem-se mais ou menos em paralelo ou ligeiramente convergentes, um pouco inclinadas, as células externas unem-se obliquamente a ambos extremos das células internas, conferindo aspecto alternado ao cenóbio. Parede celular lisa ou com verrugas irregulares localizadas nos pólos. Reprodução por quatro autósporos. Cloroplastídio parietal, com um pirenóide.

Apenas uma espécie identificada.

Tetrachlorella alternans (G.M. Smith) Koršikov, Uchenŷe zapiski Gorkovskogo gosudarstvennogo universiteta 9: 116, 126. 1939 三 Crucigenia alternans G.M. Smith, Transactions of the American Microscopical Society 45: 185, pl. 14, fig. 14-18. 1926.

Figura 10

Cenóbios planos, dispostos alternadamente, 
formados por 4 células; células oblongas, irregulares, não totalmente unidas, um pouco inclinadas, 5,8$10,7 \times 2,7-6,7 \mu \mathrm{m}$; parede celular lisa; cloroplastidio parietal, 1 pirenóide.

Hábitat: plâncton no Lago das Ninféias (SP399783); primeira citação da ocorrência da espécie.

Conforme Comas (1996), as células possuem um arranjo particular nesta espécie, pois não são planas como nos demais membros da subfamília e, além disso, não estão totalmente unidas uma à sua vizinha. A formação de grupos celulares compostos por quatro células irregularmente alternadas e mais ou menos unidas poderia situar Tetrachlorella na subfamília Scenedesmoideae ou na Crucigeniodeae, mas o gênero continua tradicionalmente classificado entre as Crucigenioideae. Segundo Komárek \& Fott (1983), entretanto, durante a reprodução os autósporos não são liberados pelo rompimento da parede celular materna e sim pela gelatinização da parede, o que poderia aproximar as Tetrachlorella das Oocystaceae.

\section{Tetrastrum R. Chodat}

Cenóbios planos mais ou menos quadrados, as vezes com um espaço central rombóide, compostos por quatro células cruzadas, às vezes com envoltura mucilaginosa, podem formar sincenóbios transitórios. Células mais ou menos triangulares, com suas margens externas arredondadas ou convexas, em algumas espécies com 1-7 espinhos orientados mais ou menos no plano do cenóbio. Cloroplasto parietal com ou sem pirenóide. Parede celular lisa ou com verrugas ou espinhos. Reprodução por 4-8 autósporos orientados no mesmo sentido que o cenóbio materno, liberando-se pelo rompimento da parede celular materna (Comas 1996).

Chave para identificação das espécies de Tetrastrum

1. Células com espinhos

2. Células com 1 espinho apenas ......... T. elegans

2. Células com mais de 1 espinho

T. heteracanthum

1. Células sem espinhos

3. Pirenóide presente T. triangulare

3. Pirenóide ausente T. komarekii

* Tetrastrum elegans Playfair, Proceedings of the Linnean Society of New South Wales 41: 832. 1917. Figura 11

Cenóbios planos, dispostos cruciadamente, pequeno espaço no centro, formados por 4 células; células subtriangulares, margens externas arredondadas, munidas de 1 espinho longo, 5,0-7,6 $\mu \mathrm{m}$ diâm., setas 13,0-20,0 $\mu \mathrm{m}$ compr.; cloroplastidio parietal, 1 pirenóide.

Hábitat: plâncton no Lago das Garças (Sant'Anna et al. 1989: 97, fig. 99).

Tetrastrum e Crucigenia são gêneros muito parecidos entre si e as caraterísticas que os separa são, segundo Nogueira (1991), a forma do espaço intercelular e a presença ou não de ornamentação em Tetrastrum. Conforme Sant'Anna (1984), Tetrastrum elegans Playfair pode ser confundida com $T$. staurogeniaeforme Lemmermann e $T$. triacanthum Koršikov devido à grande variabilidade na espessura, no número e na distribuição dos espinhos, o que faz com que estas caraterísticas não devam ser utilizadas isoladamente para delimitar essas espécies. Segundo Komárek (1974), há regularidade na distribuição e na forma desses espinhos. Segundo o último autor, em $T$. staurogeniaeforme Lemmermann os espinhos são mais espessos na base, enquanto que em T. elegans Playfair são igualmente delicados em toda sua extensão.

Tetrastrum heteracanthum (Nordstedt) R. Chodat, Bulletin de l'Herbier Boissier 3: 113. 1895.

Figuras 12-14

Cenóbios planos, células dispostas cruciadamente, pequeno espaço quadrado no centro, formados por 4 células; células arredondadas, margens externas com 2 espinhos de tamanhos desiguais, retos ou não, margens internas quase retas, 3,0-7,6 $\mu \mathrm{m}$ diâm., espinhos polares 3,0-10,8 $\mu \mathrm{m}$ compr.; cloroplastidio parietal, 1 pirenóide.

Hábitat: plâncton no Lago das Garças (SP399782; Sant'Anna et al. 1989: 97, fig. 100-101).

Tetrastrum heteracanthum (Nordstedt) R. Chodat pode ser facilmente confundida com $T$. homoiacanthum (Huber-Pestalozzi) Comas que, segundo Comas (1996), difere de T. heteracanthum (Nordstedt) R. Chodat porque seus espinhos são do mesmo tamanho, característica esta estável em $T$. homoiacanthum (Huber-Pestalozzi) Comas. Comas (1984) afirmou também que a presença, a dimensão e o número de espinhos são características diagnósticas de peso para separação de espécies do gênero, razão pela qual considerou $T$. homoiacanthum (HuberPestalozzi) Comas uma espécie independente.

Conforme Sant'Anna (1984), T. heteracanthum (Nordstedt) R. Chodat é facilmente identificável pela presença de dois espinhos de tamanhos 
desiguais por célula e pela disposição excêntrica desses espinhos na margem livre das células. Mas, Ahlstrom \& Tiffany (1934) mencionaram que o espinho pequeno nesta espécie pode não aparecer em uma ou em todas as células do cenóbio e que a espécie pode assumir, consequentemente, a forma de 'elegans'. O espinho maior varia muito quanto ao comprimento e à espessura. Pode até ocorrer num mesmo indivíduo espinhos mais frágeis e outros mais resistentes. Ainda nos espécimes observados por Ahlstrom \& Tiffany (1934), foi vista certa uniformidade com relação à curvatura dos espinhos, desde que ocorrem sempre retos e, com pouquíssimas exceções, curvados. Finalmente, o espinho pequeno geralmente alterna com o espinho longo, mas este arranjo também pode variar.

* Tetrastrum komarekii Hindák, Biologické Práce 23(4): 164. 1977.

Figura 15

Cenóbios planos, dispostos cruciadamente, espaço central pequeno, às vezes ausente, formados por 4 células, com ou sem envoltório mucilaginoso; células subtriangulares a trapezoidais, margens externas levemente convexas, arredondadas, às vezes formando sincenóbios transitórios, 10-12 × 3,0-6,0 $\mu \mathrm{m}$; cloroplastidio parietal, sem pirenóide.

Hábitat: plâncton no Lago das Garças (Tucci 2002: 244, fig. 42, Tucci et al. 2006: 165, fig. 53).

Segundo Comas (1996), parte das identificações anteriores de $T$. triangulare (R. Chodat) Komárek deve ser revista, pois se trata de T. komarekii Hindák. No entanto, pode-se questionar a existência de $T$. komarekii Hindák, desde que a única diferença entre esta espécie e T. triangulare (R. Chodat) Komárek reside na ausência de pirenóide na primeira. Conforme resultados da biologia molecular, presença ou ausência de pirenóide não tem servido universalmente para diferenciar espécies. Até que se prove o contrário, entretanto, deve-se manter $T$. komarekii Hindák.

* Tetrastrum triangulare (R. Chodat) Komárek, Archiv für Protistenkunde 116: 30, fig. 8. 1974. Figura 16

Cenóbios planos, mais ou menos quadrados, pequeno espaço no centro do cenóbio, formado por 4 células; células triangulares, dispostas cruciadamente, margens externas quase retas, às vezes levemente arredondadas, 2,5-5,5 $\times 2,4-4,6 \mu \mathrm{m}$; cloroplastidio parietal, 1 pirenóide.
Hábitat: plâncton no Lago do IAG (Ferragut et al. 2005: 156, fig. 101) e no Lago das Garças (Sant'Anna et al. 1989: 97, fig. 104).

Segundo Nogueira (1991), T. triangulare (R. Chodat) Komárek assemelha-se a Westella botryoides (W. West) De-Wildemann pela forma subesférica de suas células. No entanto, a disposição dos cenóbios filhos separa as duas espécies. Tetrastrum triangulare (R. Chodat) Komárek lembra, morfologicamente, Crucigenia tetrapedia (Kirchner) West \& West. Estas espécies podem ser separadas pelo fato da primeira possuir um espaço quadrático bem pequeno no centro do cenóbio e a segunda não, além da produção dos autósporos que em T. triangulare (R. Chodat) Komárek ocorre conforme um plano de divisão formando ângulos e em C. tetrapedia (Kirchner) West \& West em forma de cruz.

\section{Westella De-Wildeman}

Cenóbios compostos por células cruzadas, alongados em uma direção, formando geralmente sincenóbios, onde os cenóbios filhos, espacialmente ordenados, se unem por restos das paredes maternas. Parede celular lisa. Reprodução por 4-8 autósporos liberados por rompimento da parede celular materna. Cloroplastídio parietal, com um pirenóide (Comas 1996).

Apenas uma espécie identificada.

* Westella botryoides (W. West) De-Wildemann, Bulletin de l'Herbier Boissier 5: 532. $1897 \equiv$ Tetracoccus botryoides W. West, Journal of the Royal Microscopical Society 1892: 735. 1892. Figuras 17-19

Cenóbios de 4 células, às vezes formando sincenóbios de 16 ou mais de 100 células; células esféricas, 4,0-10,0 $\mu \mathrm{m}$ diâm.; cloroplastidio parietal, 1 pirenóide.

Hábitat: plâncton no Lago das Garças (Sant'Anna et al. 1989: 98, fig. 105).

Conforme Sant'Anna (1984), W. botryoides (W. West) De-Wildemann é característica pelo arranjo das células em grupos de quatro, que podem estar isolados ou ligados entre si por restos da parede da célula-mãe formando sincenóbios. A mesma autora mencionou também que esse tipo de arranjo celular lembra o de Dictyosphaerium pulchellum Wood, porém, as células com as faces planas em contato são características de Westella. Picelli-Vicentim (1987) observou que os restos de parede que ligam as células de Dictyosphaerium entre si possuem, tipicamente, a forma de fios ramificados dicotomicamente. 
Comas (1984) observou em amostras de material de Cuba populações em que as células dos cenóbios estavam fortemente unidas entre si como em Tetrastrum. No entanto, em outras populações as células apareceram menos unidas entre si, com pequenos espaços entre elas. Comas (1984) mencionou, finalmente, que este tipo de união entre as células pode ser suficiente para definir uma novidade taxonômica: uma espécie ou uma variedade nova.

\section{SUBFAMÍLIA DANUBIOIDEAE}

Cenóbios com 4 células que se tocam por um de seus extremos. Estas tétrades mais ou menos regulares podem unir-se por restos das paredes maternas para formar sincenóbios; cloroplastídio parietal, com ou sem pirenóide; parede celular lisa ou verrucosa; reprodução por 4-8 autósporos unidos em autocenóbios de 4 células, que se liberam por rompimento da parede da célula-mãe.

\section{Pseudotetrastrum Hindák}

Cenóbios mais ou menos aplanados, formados por 4 células ordenadas em um quadrado, formando sincenóbios de até 16 células, com irregularidades no ordenamento das células (secundariamente surgem grupos multicelulares ordenados espacialmente). Células tocando-se ou separadas umas das outras, cenóbios sem envoltório mucoso. Parede celular com incrustações. Cloroplastídio parietal, com pirenóide. Reprodução por 4 autósporos liberados por rompimento da parede celular materna em vários fragmentos.

Apenas uma espécie identificada.

Pseudotetrastrum punctatum (Schmidle) Hindák, Biologické Práce 23(4): 142, pl. 57, fig. 1-17. 1977 $\equiv$ Staurogenia multiseta Schmidle var. punctata Schmidle, Bericht der deutsche botanische Gesellschaft 18: 157, pl. 65, fig. 13-14. 1900.

Figura 20

Cenóbios planos, quadrados ou ligeiramente alongados, formados por 4 células unidas lateralmente, com ou sem espaços no centro do cenóbio; células mais ou menos triangulares, margens externas levemente convexas, 1,9-6,9 × 3,2-7,5 $\mu \mathrm{m}$; parede celular com verrugas derivadas de impregnações de ferro; cloroplastidio parietal, 1 pirenóide.

Hábitat: plâncton no Lago das Garças (SP399782; Sant'Anna et al. 1989: 97, fig. 102).

Sant'Anna et al. (1989) identificaram material do PEFI como Tetrastrum punctatum (Schmidle)
Ahlstrom \& Tiffany, nome hoje considerado sinônimo de Pseudotetrastrum punctatum (Schmidle) Hindák conforme Komárek \& Fott (1983).

Segundo Hindák (1977), Tetrastrum punctatum (Schmidle) Ahlstrom \& Tiffany foi transferido para outro gênero porque apresenta a parede celular granulosa na superfície, característica esta não observada nas espécies de Tetrastrum. Outra característica diferencial entre esses dois gêneros é o fato das células de Pseudotetrastrum possuírem, quando isoladas, a forma esférica. No entanto, o autor acima mencionou que esta granulação pode ser variável, tanto na forma quanto na sua localização. Esses grânulos são geralmente observados próximos das margens celulares e, menos frequentemente, na face celular.

Não consideramos satisfatórias nem suficientes as razões para transferir Pseudostaurastrum punctatum (Schmidle) Hindák para o gênero Tetrastrum, sob a combinação T. punctatum (Schmidle) Ahlstrom \& Tiffany, razão pela qual mantemos atualmente a primeira das duas combinações, como já haviam feito Komárek \& Fott (1983).

\section{SUBFAMÍLIA DIMORPHOCOCCOIDEAE}

Cenóbios com 4-8-16 células geralmente em diferentes planos; células leve ou marcadamente alternadas, tanto as externas quanto as internas, às vezes, morfologicamente bem diferenciadas, unidas por suas paredes ou por apêndices; cloroplastídio parietal, com pirenóide; parede celular lisa, às vezes, com espessamentos apicais; reprodução por 4-8 autósporos liberados por rompimento da parede da célula-mãe.

\section{Dimorphococcus A. Braun}

Alga colonial formada por numerosos grupos de quatro células. As células que constituem cada um desses grupos são, caracteristicamente, de dois tipos morfológicos: as duas mais externas possuem forma ligeiramente diferente daquela das duas localizadas mais para o interior da matriz gelatinosa. Reprodução pela formação de autósporos. Cloroplastídio com um pirenóide.

Apenas uma espécie identificada.

Dimorphococcus lunatus A. Braun, Algarum unicellularium genera nova vel minus cognita, præmissis observationibus de algis unicellularibus in genere: 44.1855.

Figura 21 


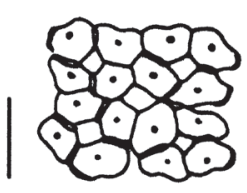

1
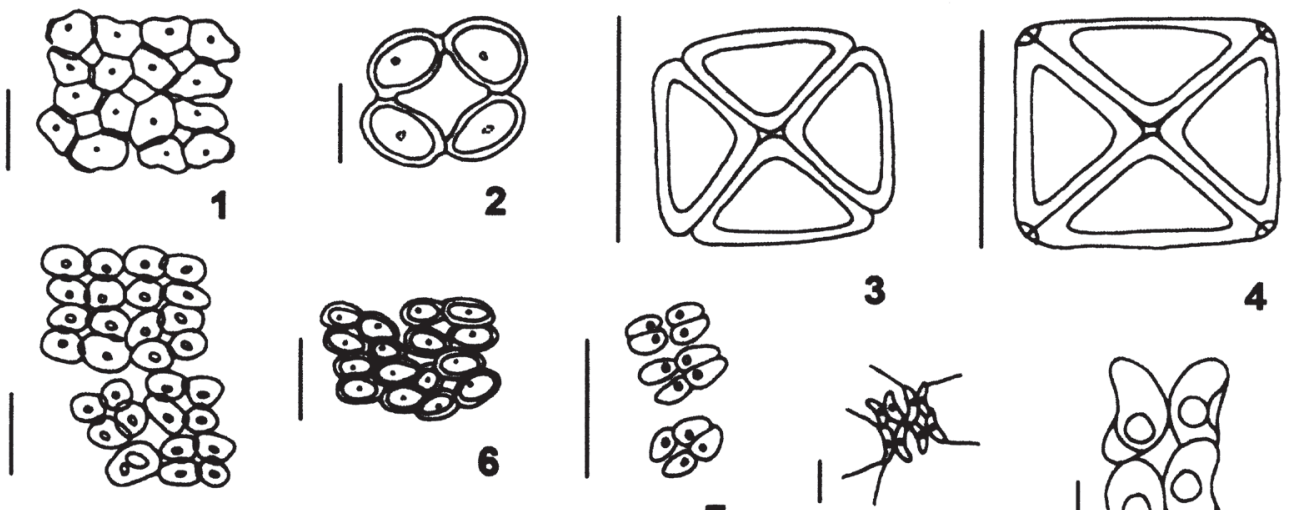

5

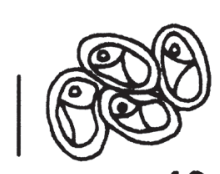

10
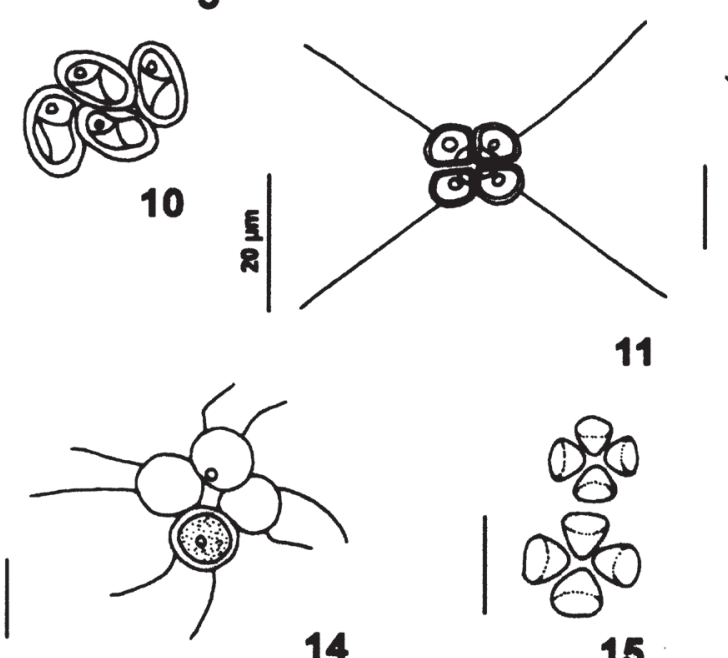

14

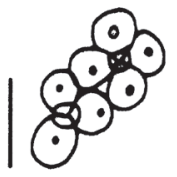

18

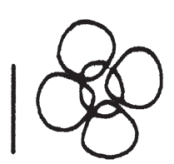

19

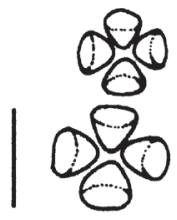

15
11

3

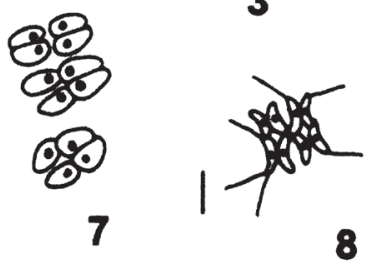

8

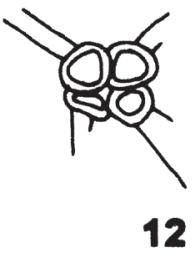

12

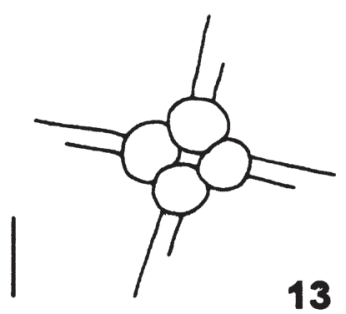

13

4

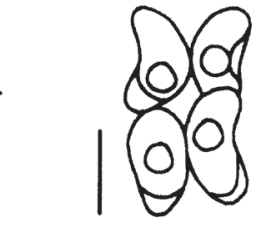

9
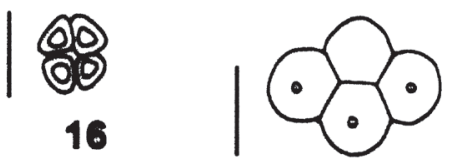

17

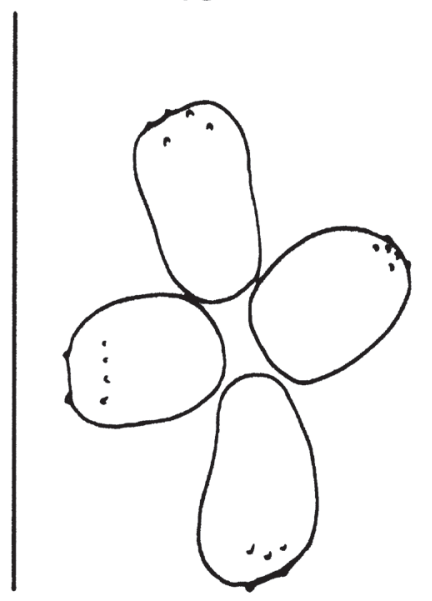

20

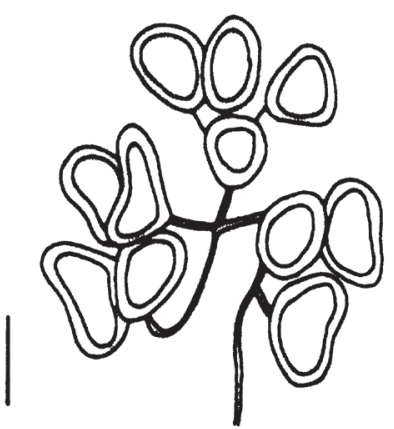

21

Figuras 1-21. Espécies de Scenedesmaceae do Parque Estadual das Fontes do Ipiranga. 1. Crucigenia mucronata. 2. Crucigenia quadrata. 3-4. Crucigenia tetrapedia. 5. Crucigeniella apiculata. 6. Crucigeniella crucifera. 7. Crucigeniella rectangularis (conforme Ferragut et al. 2005). 8. Didymogenes anomala (conforme Sant'Anna et al. 1989). 9. Didymogenes palatina (conforme Komárek \& Fott 1983). 10. Tetrachlorella alternans. 11. Tetrastrum elegans (conforme Sant'Anna 1984). 12-14. Tetrastrum heteracanthum. 15. Tetrastrum komarekii (conforme Tucci et al. 2006). 16. Tetrastrum triangulare. 17-19. Westella botryoides. 20. Pseudotetrastrum punctatum. 21. Dimorphococcus lunatus. Barras de escala $=10 \mu \mathrm{m}$, exceto quando especificamente indicado.

Figures 1-21. Species of Scenedesmaceae from the "Parque Estadual das Fontes do Ipiranga". 1. Crucigenia mucronata. 2. Crucigenia quadrata. 3-4. Crucigenia tetrapedia. 5. Crucigeniella apiculata. 6. Crucigeniella crucifera. 7. Crucigeniella rectangularis (from Ferragut et al. 2005). 8. Didymogenes anomala (from Sant'Anna et al. 1989). 9. Didymogenes palatina (from Komárek \& Fott 1983). 10. Tetrachlorella alternans. 11. Tetrastrum elegans (from Sant'Anna 1984). 12-14. Tetrastrum heteracanthum. 15. Tetrastrum komarekii (from Tucci et al. 2006). 16. Tetrastrum triangulare. 17-19. Westella botryoides. 20. Pseudotetrastrum punctatum. 21. Dimorphococcus lunatus. Scale bars $=10 \mu \mathrm{m}$, except when especifically indicated. 
Cenóbios em vários planos, formados por um número muito variável de células externas cordiformes a reniformes, unidas com as internas pela margem convexa, células internas ovaiscilíndricas, unidas pelas partes mais largas, células com pólos arredondados, podendo apresentar espessamento da parede celular. Comprimento da célula 3,35-13,7 $\mu \mathrm{m}$, diâmetro 2,5-8,3 $\mu \mathrm{m}$. Cloroplastidio parietal com um pirenóide.

Hábitat: plâncton no Lago das Garças (SP130453); primeira citação da ocorrência da espécie.

Dimorphococcus lunatus A. Braun possui, segundo Comas (1996), dois tipos morfológicos de células: (1) células externas reniformes, com a parede espessada nos pólos celulares e (2) células externas mais ou menos cordiformes, menores do que as reniformes, com a parede com ou sem espessamentos leves nos pólos. O segundo tipo é o que aparece com mais freqüência nos trópicos. Os atuais exemplares do PEFI foram indivíduos com células dimórficas, isto é, duas delas aproximadamente elípticas ou subcilíndricas e as outras duas cordadas.

\section{SUBFAMÍLIA DESMODESMOIDEAE}

Células linear ou obliquamente arranjadas em cenóbios; células com os pólos mais ou menos obtusos ou truncados; parede celular com estruturas de esporopolenina, podendo ter espinhos, costelas, dentículos ou verrugas.

\section{Desmodesmus (R. Chodat) An et al.}

Foram criadosmuitos subgêneros paraScenedesmus e, finalmente, três foram aceitos por Hegewald (1978), quais sejam: Acutodesmus, Scenedesmus e Desmodesmus. O subgênero Desmodesmus foi elevado ao nível gênero por An et al. (1999), mas os mesmos autores não conseguiram fazer o mesmo com os subgêneros Acutodesmus e Scenedesmus.

An et al. (1999) transferiram para o novo gênero somente as cinco espécies seguintes do antigo gênero Scenedesmus: D. arthrodesmiformis (Schröder) An et al., D. bicellularis (Komárek) An et al., D. denticulatus (Lagerheim) An et al., D. lefevrei Komárek e D. serratus (Corda) An et al. Hegewald (2000) transferiu o total de 55 espécies, variedades e formas taxonômicas para o gênero Desmodesmus.

O gênero Desmodesmus é constituído por indivíduos coloniais de vida livre. Os cenóbios planos são formados por 2-16 células dispostas linear ou alternadamente, com seus eixos mais longos paralelos entre si, formando uma linha de células dispostas em uma série ou em duas. As células podem ser elipsóides ou ovóides e todas iguais entre si ou de dois tipos, isto é, as externas do cenóbio são de um tipo e as internas de outro. A parede celular é ornamentada com verrugas, espinhos, dentículos ou rosetas. Os espinhos podem ocorrer tanto nos pólos das células externas, quanto nos pólos das células internas, não ocorrendo espécies sem espinhos ou sem algum tipo de ornamentação. Cloroplastídio parietal, com um pirenóide.

Chave para identificação das espécies e variedades de Desmodesmus

1. Cenóbios com células dispostas em 2 séries (alternados)

2. 1 espinho longo em cada pólo das células externas do cenóbio D. intermedius var. intermedius

2. 1-3 espinhos curtos em cada pólo das células externas do cenóbio D. denticulatus var. denticulatus

1. Cenóbios com células dispostas em 1 série (lineares)

3. Um a dois espinhos longos na margem livre das células externas do cenóbio

4. Espinhos marginais das células externas do cenóbio inseridos juntos (aos pares)

4. Espinhos marginais das células externas do cenóbio inseridos isoladamente (não aos pares)

5. Células intermediárias do cenóbio com 1 espinho longo em cada pólo D. pleiomorphus

5. Células intermediárias do cenóbio sem espinhos polares

6. Espinhos de tamanho praticamente iguais entre si D. spinosus

6. Espinhos de tamanhos diferentes entre si: os marginais das células externas maiores que os polares D. abundans

3. Um a inúmeros espinhos curtos ou uma estrutura igual a um pente na margem livre das células externas do cenóbio

7. Espinhos apenas nos pólos das células externas do cenóbio 
8. 1-2 espinhos na margem livre das células externas do cenóbio

9. Células externas do cenóbio oblongas D. armatus var. spinosus p.p.

9. Células externas do cenóbio elípticas D. spinulatus

8. Inúmeros espinhos curtos ou estrutura semelhante a um pente na margem livre das células externas do cenóbio

10. Espinhos curtos na margem livre das células externas do cenóbio

11. Dois a três espinhos nos pólos das células externas e intermediárias do cenóbio

D. pseudodenticulatus p.p.

11. Um a dois espinhos nos pólos das células externas e 1 nos pólos das células intermediárias do cenóbio

10. Estrutura semelhante a um pente na margem livre das células externas do cenóbio

12. Células oblongas D. pseudodenticulatus p.p.

12. Células elípticas D. serratus p.p.

13. Células externas do cenóbio sem espinhos D. brasiliensis

13. Células externas do cenóbio com 1-2 espinhos

14. Células externas do cenóbio com 1 espinho em um dos pólos, o outro pólo sem espinho 15. 1 espinho em cada pólo das células intermediárias do cenóbio

D. armatus var. bicaudatus

15. Sem espinhos polares nas células intermediárias (quando presentes, costelas longitudinais presentes) .......................................... D. intermedius var. acutispinus

14. Células externas do cenóbio com 1 espinho em cada pólo

16. Células elípticas a elíptico-fusiformes D. serratus p.p.

16. Células ovadas a oblongas D. armatus var. spinosus p.p.

7. Espinhos nos pólos das células externas do cenóbio e também das intermediárias.

17. Células com 1 espinho curto em cada pólo D. denticulatus var. linearis

17. Células com 1 espinho longo em cada pólo

18. Costelas e pequenos dentículos presentes nas células internas

19. Células com costelas D. armatus var. armatus

19. Células sem costelas D. opoliensis var. carinatus

18. Costelas e pequenos dentículos ausentes nas células internas

20. Células com espinhos de tamanhos diferentes nos pólos D. dispar

20. Células com espinhos de tamanhos mais ou menos iguais nos pólos

21. Células com espinhos localizados excentricamente

22. Células em contato apenas subapical D. opoliensis var. opoliensis

22. Células todas em contato D. opoliensis var. mononensis

21. Células com espinhos localizados em pólos proeminentes

23. Células com espinhos localizados em pólos proeminentes D. protuberans 23. Células muito grandes, atingindo quase $28 \mu \mathrm{m}$ compr.

24. Células com 13,6-27,8 $\mu \mathrm{m}$ compr., 4,6-8,9 $\mu \mathrm{m}$ larg. D. maximus 24. Células com 6,1-22,7 $\mu \mathrm{m}$ compr., 1,7-8,7 $\mu \mathrm{m}$ larg. D. communis

Desmodesmus abundans (Kirchner) Hegewald, Algological Studies 96: 1. 2000 三 Scenedesmus caudatus Corda f. abundans Kirchner in Cohn, Kryptogamen-Flora von Schlesien 2(1): 98. 1878. Figuras 22-27

Cenóbios planos, formados por 2-4 células dispostas linearmente; células elípticas a oblongas, pólos arredondados, células externas com 1 espinho em cada pólo e 1-2(-3) espinhos na margem, 1 espinho mais curto e 1 mais comprido, células externas variando quanto à convexidade da margem; células internas com pequenos espinhos que podem estar presentes ou ausentes, células ca. 2 vezes mais longas que largas, tão longas quanto os espinhos polares, 4,4-20,3 × 2,9-9,0 $\mu \mathrm{m}$, espinhos polares 4-8,5 $\mu \mathrm{m}$ compr., espinhos marginais $2,0-6,0 \mu \mathrm{m}$ compr., às vezes espinhos polares pequenos, proporcionais à largura da célula; cloroplastidio parietal, 1 pirenóide. 
Hábitat: plâncton no Lago do IAG (SP399779); primeira citação da ocorrência da espécie.

Desmodesmus abundans (Kirchner) Hegewald é facilmente confundida com D. spinosus (R. Chodat) Hegewald, no entanto, a diferença entre essas espécies reside no fato de D. abundans (Kirchner) Hegewald possuir dois espinhos de tamanhos desiguais nas margens externas das células. Os espinhos desta última espécie também podem ocorrer isolados ou, mais raramente, em número de três. Em $D$. spinosus (R. Chodat) Hegewald, os espinhos marginais são praticamente do mesmo tamanho, ocorrem em número muito maior por célula e se distribuem por toda a parede celular em todo cenóbio. Os representantes de D. spinosus (R. Chodat) Hegewald possuem costelas laterais e, além disso, uma tendência à desagregação dos cenóbios em células isoladas.

Difere também de D. pleiomorphus (Hindák) Hegewald por que, nesta última, as células internas possuem espinhos grandes, enquanto que em $D$. abundans (Kirchner) Hegewald ocorrem somente espinhos muito curtos.

Encontramos variação morfológica considerável nas populações examinadas de D. abundans (Kirchner) Hegewald. Variou o número de células dos cenóbios, ora com duas ora com quatro células. Variaram também os espinhos, aparecendo um espinho longo nos pólos das células externas e, no mínimo, um espinho no centro da margem da célula externa, além de pequenos espinhos nas células internas. Variou ainda a forma da célula, que ora apareceu oblonga, ora elíptica com uma convexidade bem acentuada no centro da margem externa, no local de onde sai o espinho da margem externa da célula. Variou, finalmente, a espessura dos espinhos, que ora apareceram bem finos e ora bastante espessos.

Desmodesmus armatus (R. Chodat) Hegewald var. armatus, Algological Studies 96: 2. $2000 \equiv$ Scenedesmus hystrix Lagerheim var. armatus R. Chodat, Algues Vertes de Suisse. 215, fig. 140. 1920.

Figuras 28-32

Cenóbios planos, lineares, formados por 2-4 células; células elípticas, pólos arredondados a fusiformes, células externas com 1 espinho em cada pólo, células internas podem apresentar pequenos espinhos, com costelas longitudinais medianas e rosetas (raramente), 5,4-15,9 (literatura 14,0-18,0 $\mu \mathrm{m}) \times 1,9-5,3 \mu \mathrm{m}$ (literatura 5,0-8,0 $\mu \mathrm{m}$ ), espinhos polares $4-14 \mu \mathrm{m}$ compr. (literatura $10,0-20,0 \mu \mathrm{m}$ ); cloroplastidio parietal, 1 pirenóide.

Hábitat: plâncton no Lago do IAG (SP399779, SP399780; Ferragut et al. 2005: 153, fig. 75) e no Lago das Garças (SP399781, SP399782; Sant'Anna et al. 1989: 96, fig. 83, como Scenedesmus ellipsoideus R. Chodat).

Desmodesmus armatus (R. Chodat) Hegewald é uma espécie relativamente comum nas amostras analisadas, porém, não tão fácil de ser identificada. É morfologicamente muito parecida com $D$. communis (Hegewald) Hegewald, da qual difere pela presença de costelas. Desmodesmus armatus (R. Chodat) Hegewald apresenta grande variação morfológica tanto na dimensão das células quanto no comprimento dos espinhos e na presença de costelas. Os espinhos polares da última espécie são, em geral, bastante longos e espessos, no entanto, podem variar e também podem existir pequenos espinhos polares nas células internas. As costelas também podem estar presentes, além de aparecerem inteiras cortando todo o eixo longitudinal ou ocorrerem fragmentadas.

Desmodesmus armatus (R. Chodat) Hegewald é, conforme Hindák (1990) e Hegewald (2000), uma das espécies cujos caracteres diagnósticos apresentam ampla variabilidade. Observou-se, consequentemente, que é necessário extremo cuidado durante o processo de identificação desta espécie, pois essa considerável variação morfológica o torna, em vários momentos, problemático.

Desmodesmus armatus (R. Chodat) Hegewald var. bicaudatus (Guglielmetti) Hegewald, Algological Studies 96: 4. 2000 EScenedesmus acutiformis Schröder var. bicaudatus Guglielmetti, Nuova Notarisia 21: 31. 1910.

Figuras 33-36

Cenóbios planos, lineares, formados por 2-4 células; células elípticas, pólos arredondados, células externas com 1 espinho em apenas um dos pólos, dispostos em sentidos opostos (diagonalmente), espinhos menores em toda extensão da margem das células externas, (como um pente), células internas com ou sem pequenos espinhos curtos, costelas longitudinais medianas em toda extensão celular ou fragmentadas, costelas também podem aparecer como uma estria longitudinal, 6,0-13,9 × 1,5-6,0 $\mu \mathrm{m}$, espinhos polares 5,0-13,0 $\mu \mathrm{m}$ compr.; cloroplastidio parietal, 1 pirenóide.

Hábitat: plâncton no Lago das Garças (SP399781, SP399782; Moura 1996: 49, fig. 18, como Scenedesmus semipulcher Hortobágyi; Tucci et al. 
2006: 165, fig. 51, como Scenedesmus semipulcher Hortobágyi) e no Lago do IAG (Ferragut et al. 2005: 153, fig. 76).

Desmodesmus armatus (R. Chodat) Hegewald var. bicaudatus (Guglielmetti) Hegewald difere da variedade típica da espécie pelo seu caracter bicaudado.

A espécie é considerada comum no Lago das Garças e no Lago do IAG e de fácil identificação taxonômica. Foram encontrados espécimes com cenóbios formados por duas ou quatro células. A forma da célula também foi considerada um caracter bastante variável dentro da espécie, variando o tamanho e a forma das células externas que, em alguns espécimes, chegam a ser elípticas, no entanto, com os pólos aproximadamente truncados. Variou também o tamanho dos espinhos dos pólos das células externas e a presença ou ausência de diminutos espinhos nos pólos das células internas. Presença ou ausência de costelas também pode ser um caracter variável dentro da espécie, entretanto, a presença de diminutos espinhos situados muito próximos uns dos outros, que percorrem toda a extensão da margem das células externas como se fosse um pente, foi o caracter mais estável desta espécie.

Desmodesmus armatus (R. Chodat) Hegewald var. spinosus (Fritsch \& Rich) Hegewald, Algological Studies 96: 5. $2000 \equiv$ Scenedesmus armatus var. spinosus Fritsch \& Rich, Transactions of the Royal Society of South Africa 18: 31, fig. 5a-c. 1929.

Figuras 37-38

Cenóbios planos, lineares, formados por 4-8 células; células ovadas a oblongas, ca. 3 vezes mais longas que largas, pólos arredondados a fusiformes, células externas e internas com 1-3 espinhos nos pólos, costelas medianas longitudinais em toda extensão da parede celular, espinhos diminutos presentes ou não, bem próximos uns dos outros, percorrendo toda extensão da margem das células externas, 10,2-20,3 $\times 3,0-7,8 \mu \mathrm{m}$, espinhos polares $2,0-3,0 \mu \mathrm{m}$ compr.; cloroplastidio parietal, 1 pirenóide.

Hábitat: plâncton no Lago das Ninféias (SP399783); primeira citação da ocorrência da variedade.

De acordo com Hegewald (2000), esta variedade inclui Scenedesmus praetervisus R. Chodat e S. soli Hortobágyi. Scenedesmus denticulatus Lagerheim var. linearis Hansgirg f. costato-granulatus (Hortobágyi) Uherkovich e $S$. denticulatus Lagerheim var. linearis Hansgirg f. granulatus Hortobágyi foram incluídos por Hegewald (2000) em D. armatus (R. Chodat) Hegewald var. spinosus (Fritsch \& Rich) Hegewald.

A existência de espinhos nos pólos das células internas do cenóbio é um caracter muito variável dentro da espécie. Além deste, os espinhos diminutos situados muito próximos uns dos outros e que percorrem toda a extensão da margem das células externas à semelhança de um pente também foi um caracter bastante variável desta espécie. A característica mais estável da espécie foi a presença de costelas.

Desmodesmus brasiliensis (Bohlin) Hegewald, Algological Studies 96: 7. $2000 \equiv$ Scenedesmus brasiliensis Bohlin, Bihang till K. Svenska vetenskapsakademiens handlingar: sér. 3, 23(7): 22, pl. 1, fig. 36-37. 1897.

Figuras 39-43

Cenóbios planos, lineares, formados por 2-4 células; células elípticas a oblongas, pólos arredondados, células externas e internas com 1-2 $(-3)$ pequenos espinhos que podem aparecer em todas as células do cenóbio ou não, costelas longitudinais medianas ao longo de toda extensão celular ou fragmentada, células externas com ou sem rosetas, células externas geralmente com espinhos diminutos na margem da célula (como pente) e uma membrana que envolve o pente, 7,0-21,3 $\times 2,0-5,9 \mu \mathrm{m}$, espinhos polares 1,0-3,0 $\mu \mathrm{m}$ compr.; parede celular lisa ou granulada em toda extensão; cloroplastidio parietal, 1 pirenóide.

Hábitat: plâncton no Lago das Ninféias (SP399783); primeira citação da ocorrência da espécie.

Desmodesmus brasiliensis (Bohlin) Hegewald é uma espécie muito comum, cosmopolita e que apresenta considerável variação morfológica. As células elípticas a oblongas são um caracter estável na espécie, porém, os espinhos polares podem variar entre um e dois, raramente três, em todas as células do cenóbio, tanto nas externas quanto nas internas. As células externas geralmente possuem espinhos diminutos muito próximos da margem da célula, os quais lembram um pente, e uma membrana que envolve este pente. Esta estrutura é característica da espécie. No entanto, D. brasiliensis (Bohlin) Hegewald pode ser facilmente confundido com Scenedesmus serratus (Corda) Bohlin devido ao fato deste último também apresentar tal estrutura; mas, S. serratus (Corda) Bohlin apresenta espinhos marginais independentes, mais separados um do outro do que em D. brasiliensis (Bohlin) Hegewald. 
<smiles>CCc1c(C)cc(C)c(CC)c1CC</smiles>

22

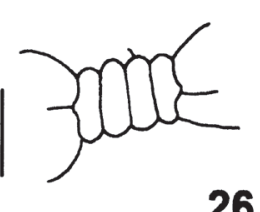

26

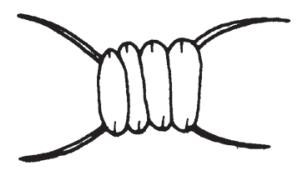

30

23

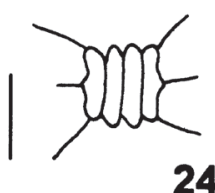

24

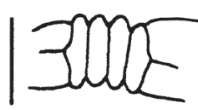

25

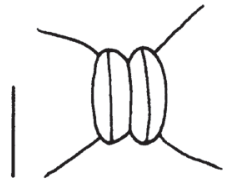

29

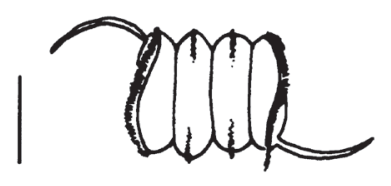

33

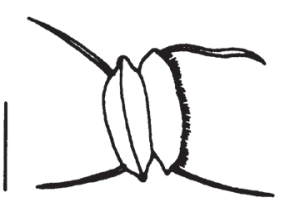

31

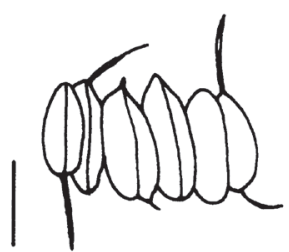

32

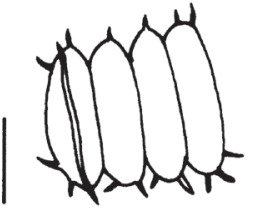

37

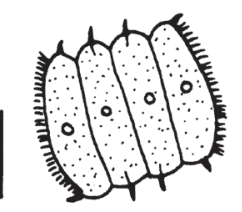

38

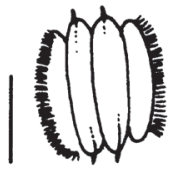

39

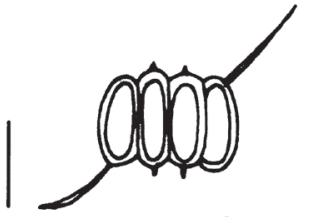

35

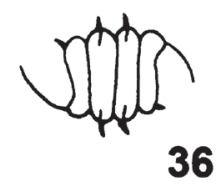

36
34

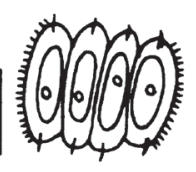

40

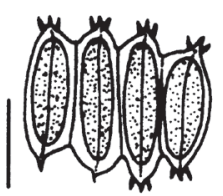

41

Figuras 22-41. Espécies de Scenedesmaceae do Parque Estadual das Fontes do Ipiranga. 22-27. Desmodesmus abundans. 28-32. Desmodesmus armatus var. armatus. 33-36. Desmodesmus armatus var. bicaudatus. 37-38. Desmodesmus armatus var. spinosus. $39-41$. Desmodesmus brasiliensis. Barras de escala $=10 \mu \mathrm{m}$, exceto quando especificamente indicado.

Figures 22-41. Species of Scenedesmaceae from the "Parque Estadual das Fontes do Ipiranga". 22-27. Desmodesmus abundans. 28-32. Desmodesmus armatus var. armatus. 33-36. Desmodesmus armatus var. bicaudatus. 37-38. Desmodesmus armatus var. spinosus. $39-41$. Desmodesmus brasiliensis. Scale bars $=10 \mu \mathrm{m}$, except when especifically indicated. 
Além disso, também podem variar as costelas, que ora estão presentes ora ausentes e aparecerem inteiras, cortando todo o eixo longitudinal da célula, ou fragmentadas. A parede celular também varia, podendo aparecer lisa ou apresentar granulações.

Desmodesmus communis (Hegewald) Hegewald, Algological Studies 96: 8. 2000 三 Scenedesmus communis Hegewald, Algological Studies 19: 151, fig. 12-13. 1977.

Figuras 44-47

Cenóbios planos, lineares, formados por 2-4 células; células elípticas a oblongas, pólos arredondados, células externas com 1 espinho em cada pólo, células internas destituídas de espinhos, $6,1-22,7 \times 1,7-8,7 \mu \mathrm{m}$, espinhos polares 2,0-22,5 $\mu \mathrm{m}$ compr.; cloroplastidio parietal, 1 pirenóide.

Hábitat: plâncton no Lago das Garças (SP399781, SP399782; Sant'Anna et al. 1989: 97, fig. 92-93, como Scenedesmus quadricauda (Turpin) Brébisson; Gentil 2000: 55, fig. 16, como Scenedesmus quadricauda (Turpin) Brébisson), no Lago das Ninféias (SP399783) e no Lago do IAG [Ferragut et al. 2005: 153, fig. 81, como Desmodesmus opoliensis (P. Richter) Hegewald var. opoliensis; Ferragut et al. 2005: 156, fig. 99, como Scenedesmus quadricauda (Turpin) Brébisson 'sensu' R. Chodat].

Desmodesmus communis (Hegewald) Hegewald é amplamente conhecida como Scenedesmus quadricauda (Turpin) Brébisson. Características bastante variáveis nesta espécie são as dimensões celulares e dos espinhos.

A espécie é considerada cosmopolita. Apesar de ser facilmente encontrada, é extremamente variável tanto nas dimensões quanto no número e no tamanho dos espinhos, nas dimensões celulares, além do número de células no cenóbio, o que torna um tanto complicada sua identificação taxonômica.

Desmodesmus denticulatus (Lagerheim) An et al. var. denticulatus, Algological Studies 96: 9. 2000 三Scenedesmus denticulatus Lagerheim, Öfversigt af Kungliga Vetenskapsakademiens förhandlingar 39(2): 61, pl. 2, fig. 13-16. 1882.

Figura 48

Cenóbios planos, alternados, formados por 4 células; células oblongas, assimétricas, pólos arredondados, células externas e internas com 1-3 espinhos pequenos nos pólos, 10,4-14,7 × 5,5-7,6 $\mu \mathrm{m}$, espinhos polares 2,0-3,0 $\mu \mathrm{m}$ compr.; cloroplastidio parietal, 1 pirenóide.
Hábitat: plâncton no Lago das Garças (SP399782; Sant'Anna et al. 1989: 96, fig. 68-69, como Scenedesmus arcuatus Lemmermann f. spinosus Hortobágyi \& Németh; Sant'Anna et al. 1989: 96, fig. 84-85, como Scenedesmus denticulatus Lagerheim).

Desmodesmus denticulatus (Lagerheim) An et al. é uma espécie bem delimitada e de fácil identificação taxonômica. Segundo Comas (1996), existem características bem marcantes nesta espécie, que são: as quatro células iguais e alternas são iguais entre si e possuem um a quatro dentículos orientados paralelamente entre si ou ligeiramente inclinados em relação ao cenóbio. Vale, entretanto, lembrar que $D$. denticulatus (Lagerheim) An et al. var. denticulatus é morfologicamente muito parecida com $D$. spinulatus (Biswas) Hegewald, porém, diferem na forma da célula que na primeira é oblonga e assimétrica e na segunda, elíptico-fusiforme, com os pólos truncados. Foram encontradas somente pequenas populações de $D$. denticulatus (Lagerheim) An et al. var. denticulatus, entretanto, seus exemplares constituintes apresentaram todas as características diagnósticas da espécie.

Desmodesmus denticulatus (Lagerheim) An et al. var. linearis (Hansgirg) Hegewald, Algological Studies 96: 10. 2000 三 Scenedesmus denticulatus Lagerheim var. linearis Hansgirg, Prodromus der Algenflora von Böhmen 1: 268. 1888.

Figuras 49-52

Cenóbios planos, lineares, formados por 4-8 celulas; células oblongas, pólos arredondados, células externas bem convexas na parte mediana, células externas e internas com pequenos espinhos retos, 5,3$20,0 \mu \mathrm{m} \times 2,2-8,0 \mu \mathrm{m}$, espinhos polares $1,0-3,0 \mu \mathrm{m}$ compr.; cloroplastidio parietal, 1 pirenóide.

Hábitat: plâncton no Lago das Ninféias (SP399783), no Lago das Garças [Sant'Anna et al. 1989: 96, fig. 79, como Scenedesmus brevispina (G.M. Smith) R. Chodat; Sant'Anna et al. 1989: 96, fig. 86, como Scenedesmus denticulatus Lagerheim var. australis Playfair] e no Lago do IAG [Ferragut et al. 2005: 153, fig. 77, como Desmodesmus denticulatus (Lagerheim) An et al. var. linearis (Hansgirg) Hegewald].

Desmodesmus denticulatus (Lagerheim) An et al. var. linearis (Hansgirg) Hegewald possui originalmente, conforme Nogueira (1991), disposição linear das células no cenóbio, no que difere dos representantes da variedade típica da espécie, que têm arranjo alternado. $\mathrm{O}$ material ora examinado apresenta dois espinhos diminutos nos pólos, o que 
também constitui uma diferença da variedade típica da espécie, que apresenta de um a quatro espinhos diminutos em cada pólo celular (Sant'Anna 1984).

Sant'Anna et al. (1989) e Ferragut et al. (2005) documentaram a presença de representantes de $D$. denticulatus (Lagerheim) An et al. var. linearis (Hansgirg) Hegewald em ambientes do PEFI com dois dentículos em cada uma das duas células do cenóbio. Nenhum espécime deste tipo foi encontrado nas populações ora estudadas. Consideramos, entretanto, os espécimes em Sant'Anna et al. (1989) e Ferragut et al. (2005) uma expressão do espectro da variação morfológica da referida atual var. linearis (Hansgirg) Hegewald.

Desmodesmus dispar (Brébisson) Hegewald, Algological Studies 96: 10. 2000 三 Scenedesmus dispar Brébisson, Mémoires de la Société Imperiale des Sciences Naturelles de Cherbourg 4: 159, pl. I, fig. 32. 1856.

Figuras 53-54

Cenóbios planos, lineares, formados por 2-4 células; células elípticas, pólos arredondados; células externas com 1 espinho médio disposto diagonalmente oposto ao outro em um dos pólos e 1 pequeno espinho também disposto diagonalmente oposto ao outro no outro pólo, às vezes rosetas nas células externas, células internas com pequenos espinhos curvos, voltados para baixo, que também podem ser retos, 8,4-13,9 × 2,6-5,9 $\mu \mathrm{m}$, espinhos polares 2,0-10,0 $\mu \mathrm{m}$ compr.; cloroplastidio parietal, 1 pirenóide.

Hábitat: plâncton no Lago do IAG (SP399779, SP399780; Ferragut et al. 2005: 155, fig. 91, como Scenedesmus danubialis Hortobágyi) e no Lago das Ninféias (SP399783).

Desmodesmus dispar Brébisson possui uma característica diagnóstica bastante expressiva, que são células externas com um espinho de tamanho médio localizado diagonalmente oposto ao outro em um dos pólos e um espinho pequeno também situado diagonalmente oposto ao outro no outro pólo. Além dessa característica, há ainda espinhos nas células internas que também podem ser extremamente variáveis, podendo ser retos e paralelos ao eixo longitunial a convexos ou côncavos. É importante notar, entretanto, que as formas bicaudadas podem ser confundidas com representantes de D. armatus (R. Chodat) Hegewald var. bicaudatus (Guglielmetti) Hegewald.

Ferragut et al. (2005) identificaram material coletado no Lago do IAG como Scenedesmus danubialis Hortobágyi. O reexame desse material permitiu, entretanto, concluir que se trata de $D$. dispar Brébisson.

Desmodesmus flavescens (R. Chodat) Hegewald var. breviaculeatus (Bourrelly) Hegewald, Algological Studies 96: 10. 2000 三 Scenedesmus tenuispina R. Chodat var. breviaculeatus Bourrelly, Bibliotheca Phycologica 76: 57, pl. 23, fig. 7-9. 1987.

Figuras 55-56

Cenóbios planos, lineares, formados por 2 células; células elípticas, pólos arredondados, células com 1-3 espinhos pequenos nos pólos, além de 1 par de espinhos equatoriais na parte mediana da célula próxima da margem externa, 11,2-13,0 × 3,2-7,0 $\mu \mathrm{m}$, espinhos polares $2,0-4,0 \mu \mathrm{m}$ compr.; cloroplastidio parietal, 1 pirenóide.

Hábitat: plâncton no Lago do IAG (SP399780; Ferragut et al. 2005: 155, fig. 94, como Scenedesmus gutwinskii R. Chodat) e no Lago das Garças (SP399782).

Komárek \& Fott (1983) mencionaram somente cenóbios de quatro células, no entanto, nas amostras ora examinadas foram vistos indivíduos com duas células. Mas, concordamos com os referidos autores quando afirmaram que a existência de dois espinhos laterais equatoriais na célula externa é a característica diagnóstica da espécie.

Desmodesmus flavescens (R. Chodat) Hegewald var. breviaculeatus (Bourrelly) Hegewald difere de D. abundans (Kirchner) R. Chodat por apresentar espinhos laterais equatoriais. Difere também da variedade típica da espécie por conta do tamanho dos espinhos, que na última são muito maiores do que na var. breviaculeatus (Bourrelly) Hegewald. Difere, finalmente, de S. gutwinskii R. Chodat porque a última espécie não apresenta espinhos equatoriais $\mathrm{e}$ sim laterais.

Ferragut et al. (2005) identificaram Scenedesmus gutwinskii R. Chodat a partir de material coletado no Lago do IAG, no entanto, esse material é idêntico a $D$. flavescens (R. Chodat) Hegewald var. breviaculeatus (Bourrelly) Hegewald. O mesmo sucedeu com o material em Sant'Anna et al. (1989) identificado com Scenedesmus gutwinskii R. Chodat que também se trata de $D$. flavescens (R. Chodat) Hegewald var. breviaculeatus (Bourrelly) Hegewald.

* Desmodesmus intermedius (R. Chodat) Hegewald var. intermedius, Algological Studies 96: 11. 2000 
三Scenedesmus intermedius $\mathrm{R}$. Chodat, Zeitschrift

für Hydrologie 3: 231, fig. 135. 1926.

Figura 57

Cenóbio planos, alternados, formados por 4 células; células elíptico-oblongas, pólos arredondados, células externas com espinhos longos nos pólos, células internas sem espinhos pequenos, 4,5-12,8 × 3,0-5,4 $\mu \mathrm{m}$, espinhos polares 3,5-13,0 $\mu \mathrm{m}$ compr.; cloroplastidio parietal, 1 pirenóide.

Hábitat: plâncton no Lago do IAG [Ferragut et al. 2005: 153, fig. 79, como Desmodesmus intermedius (R. Chodat) Hegewald var. intermedius] e no Lago das Garças (Sant'Anna et al. 1989: 97, fig. 87, como Scenedesmus intermedius R. Chodat).

Nas amostras presentemente analisadas, $D$. intermedius (R. Chodat) Hegewald var. intermedius apresentou cenóbios formados por células ovóides distribuídas alternadamente, características estas diagnósticas da espécie e que permitiram identificar, sem sombra de dúvida, os poucos exemplares encontrados. Os espécimes ora analisados não apresentaram espinhos polares nas células internas sendo, por isso, semelhantes aos estudados por Sant'Anna et al. (1989) e Nogueira (1991), mas diferentes daqueles em Ferragut et al. (2005), que apresentaram espinhos nas células internas do cenóbio.

Desmodesmus intermedius (R. Chodat) Hegewald var. acutispinus (Roll) Hegewald, Algological Studies 96: 12. 2000. EScenedesmus quadricauda (Turpin) Brébisson var. acutispinus Roll, Russkiî arkhiv protistologii 4: 144, 149. 1925.

Figuras 58-60

Cenóbios planos, lineares, formados por 2-8 células; células elípticas, pólos arredondados, células externas com 1 espinho em apenas um dos pólos, dispostos em sentidos opostos (diagonalmente), células internas com ou sem espinhos pequenos, costelas longitudinais medianas às vezes presentes, 6,2-12,8 × 1,9-5,3 $\mu \mathrm{m}$, espinhos polares 3,0-14,0 $\mu \mathrm{m}$ compr.; cloroplastidio parietal, 1 pirenóide.

Hábitat: plâncton no Lago das Garças (SP399781, SP399782; Sant'Anna et al. 1989: 96, fig. 76, como Scenedesmus bicaudatus Dedusenko; Gentil 2000: 55, fig. 14, como Scenedesmus bicaudatus Dedusenko), no Lago das Ninféias (SP399783) e no Lago do IAG [Ferragut et al. 2005: 153, fig. 78, como Desmodesmus intermedius (R. Chodat) Hegewald var. acutispinus (Roll) Hegewald].

Desmodesmus intermedius (R. Chodat)
Hegewald var. acutispinus (Roll) Hegewald é uma espécie comum, facilmente encontrada nas amostras analisadas. É também uma espécie de fácil identificação taxonômica por conta dos dois espinhos inclinados, opostos, arranjados diagonalmente nas células externas do cenóbio. Tais espinhos podem variar de tamanho de um indivíduo para outro. Quando os espinhos são muito pequenos, os espécimes que os possuem podem ser confundidos com os de Scenedesmus bicaudatus (Hansgirg) R. Chodat var. brevicaudatus Hortobágyi. É possível que tais espécimes representantes desta variedade nada mais sejam do que uma variação morfológica da espécie e não uma variedade taxonômica propriamente dita.

A var. acutispinus (Roll) Hegewald acima referida é muito parecida com $D$. armatus $\mathrm{R}$. Chodat var. bicaudatus (Guglielmetti) Hegewald, porém, diferem porque a última apresenta espinhos diminutos em toda margem das células externas, que lembram um pente, ou seja, uma estrutura que não ocorre em $D$. intermedius (R. Chodat) Hegewald var. acutispinus (Roll) Hegewald. Além disso, o cenóbio nesta última espécie é constituído por células alternadas enquanto que na primeira é linear.

Sant'Anna (1984), Gentil (2000) e Ferragut et al. (2005) ilustraram espécimes com cenóbios lineares, o que mostra que cenóbios lineares e alternados são variações dentro da espécie e que tal característica não deve ser considerada um bom critério para definição desta espécie. Além da variação morfológica do cenóbio, D. intermedius (R. Chodat) Hegewald var. acutispinus (Roll) Hegewald também apresentou grande variação com relação à presença ou ausência de costelas, à presença ou ausência de pequenos espinhos polares nas células internas e com relação ao tamanho dos espinhos.

Hegewald et al. (1988) afirmou que S. intermedius R. Chodat é uma espécie muito variável, podendo apresentar células ovais ou alongadas, dispostas linear ou alternadamente no cenóbio, com costelas ou não, com espinhos nas células externas ou não, com espinhos nas células internas ou não e bicaudados ou quadricaudados. O que verdadeiramente caracteriza esta espécie é a ultra-estrutura da parede.

* Desmodesmus maximus (West \& West) Hegewald, Algological Studies 96: 13. $2000 \equiv$ Scenedesmus quadricauda (Turpin) Brébisson var. maximus West \& West, Transactions of the Linnean Society of London: série Botânica, 5: 83. 1895. 


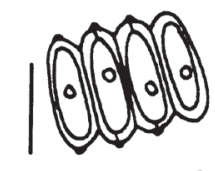

42

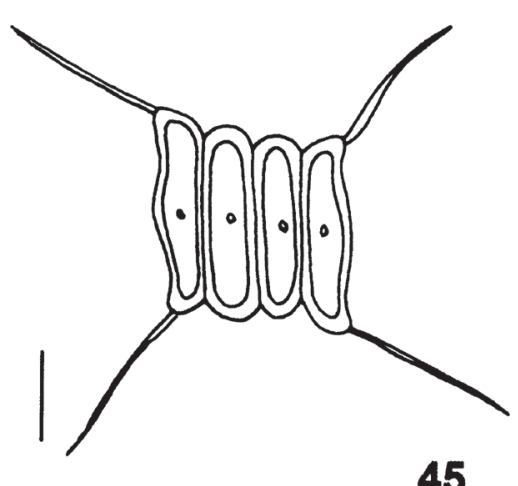

43

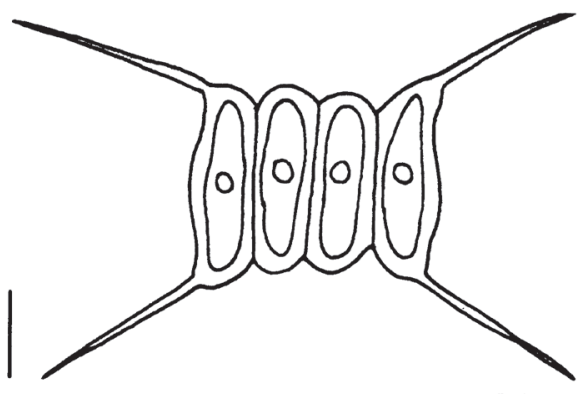

44
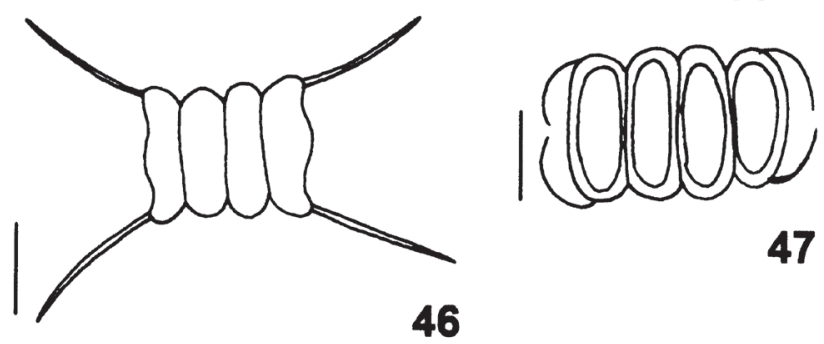

47

46

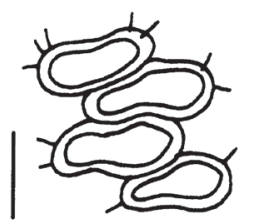

48

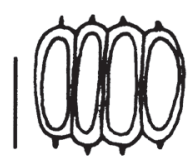

49

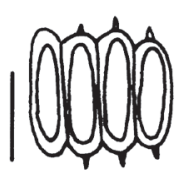

50

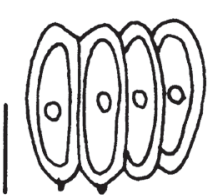

51

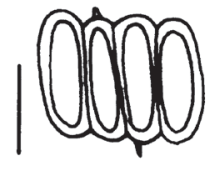

52

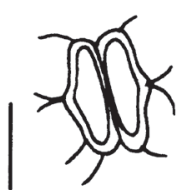

55

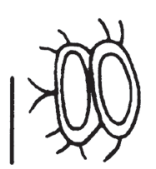

56

53

54

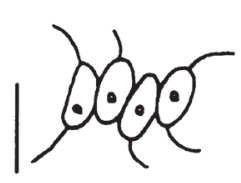

57

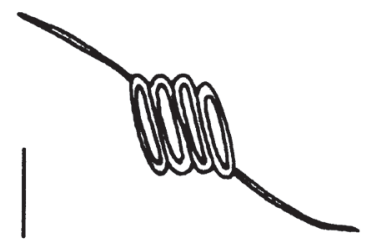

58
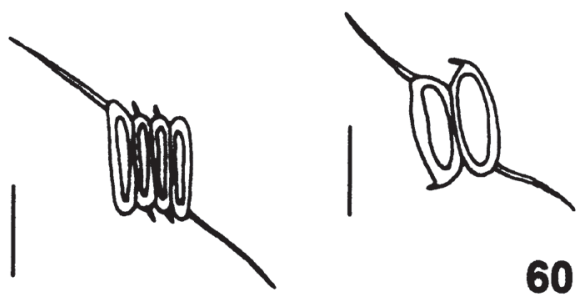

60

59

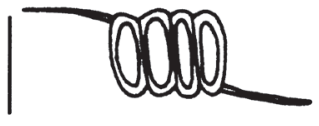

61

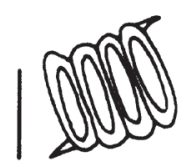

62

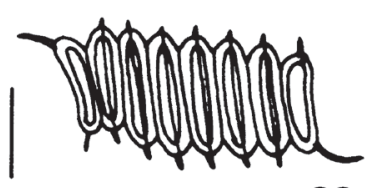

63

Figuras 42-63. Espécies de Scenedesmaceae do Parque Estadual das Fontes do Ipiranga. 42-43. Desmodesmus brasiliensis. $44-47$. Desmodesmus communis. 48. Desmodesmus denticulatus var. denticulatus. 49-52. Desmodesmus denticulatus var. linearis. 53-54. Desmodesmus dispar. 55-56. Desmodesmus flavescens var. breviaculeatus. 57. Desmodesmus intermedius var. intermedius (conforme Ferragut et al. 2005). 58-63. Desmodesmus intermedius var. acutispinus. Barras de escala $=10 \mu$ m, exceto quando especificamente indicado.

Figures 42-63. Species of Scenedesmaceae from the "Parque Estadual das Fontes do Ipiranga". 42-43. Desmodesmus brasiliensis. 4447. Desmodesmus communis. 48. Desmodesmus denticulatus var. denticulatus. 49-52. Desmodesmus denticulatus var. linearis. 53-54. Desmodesmus dispar. 55-56. Desmodesmus flavescens var. breviaculeatus. 57. Desmodesmus intermedius var. intermedius (from Ferragut et al. 2005). 58-63. Desmodesmus intermedius var. acutispinus. Scale bars $=10 \mu \mathrm{m}$, except when especifically indicated. 
Figuras 64-66

Cenóbios planos, lineares, formados por 2-16 células; células oblongas, grandes, bem desenvolvidas, pólos arredondados, células externas com 1 espinho em cada pólo, células internas sem espinhos, células externas às vezes com espinhos acentuadamente curvos, 13,6-27,8 × 4,6-8,9 $\mu \mathrm{m}$, espinhos polares 5,0-25,0 $\mu \mathrm{m}$ compr.; cloroplastidio parietal, 1 pirenóide.

Hábitat: plâncton no Lago do IAG [Ferragut et al. 2005: 153, fig. 80, como Desmodesmus maximus (West \& West) Hegewald].

Desmodesmus maximus (West \& West) Hegewald pode ser confundido com D. communis (Hegewald) Hegewald, mas difere pelo tamanho das células, que na primeira espécie são bastante maiores.

A presente variedade foi considerada por Hegewald (2000) uma simples variação morfológica de D. maximus (West \& West) Hegewald, caracterizada pela ausência de dentículos e de verrugas nas células externas e de espinhos nas células internas do cenóbio.

* Desmodesmus opoliensis (P. Richter) Hegewald var. opoliensis, Algological Studies 96: 14. 2000

三Scenedesmus opoliensis P. Richter, Zeitschrift angewandte Mikroskopie und Klinische Chemie 1: 3, 7. fig. a-e. 1895 .

Figura 67

Cenóbios planos, lineares ou alternados, formados por 2-4 células; células elípticas a fusiformes, pólos agudos, truncados, células externas com 1 protuberância de onde sai 1 espinho longo, excêntrico, células internas em contato pela parte subapical, com ou sem espinhos pequenos nos pólos, 8,0-28,0 × 2,5-9,0 $\mu \mathrm{m}$, espinho 10,0-28,0 $\mu \mathrm{m}$ compr.; parede celular lisa ou ornamentada com costelas; cloroplastidio parietal, 1 pirenóide.

Hábitat: plâncton no Lago das Garças (Sant'Anna et al. 1989: 97, fig. 90, como Scenedesmus opoliensis P. Richter).

Scenedesmus opoliensis (P. Richter) Hegewald apresenta células desde elipsóides até fusiformes. Conforme Comas (1996), os extremos são atenuados e os pólos mais ou menos truncados nas células externas. As células externas são arqueadas e as internas retas. Os espinhos estão inseridos nos ângulos dos pólos das células externas do cenóbio. A característica diagnóstica de D. opoliensis (P. Richter) Hegewald são esses espinhos localizados excentricamente nas células externas do cenóbio.
Tal característica permite diferenciar esta espécie de outras como, por exemplo, de D. protuberans (Fritsch $\&$ Rich) Hegewald. Outra característica importante da variedade típica da espécie é a formação de um tipo de cenóbio em que as células podem estar dispostas linear ou alternadamente, porém, sem se contactar totalmente, mas apenas pela região próxima dos pólos (subapicalmente), o que vai diferenciar a variedadetipo da var. mononensis (R. Chodat) Hegewald, que tem as células do cenóbio inteiramente em contato.

Nem sempre é possível observar a localização exata dos pólos, especialmente se a base dos espinhos for muito grossa e quando os pólos celulares são mais alongados. Por isso, muitos especialistas duvidam do uso deste caracter como diagnóstico. No atual estudo, foi documentada a localização excêntrica dos espinhos em todos os espécimes observados.

* Desmodesmus opoliensis (P. Richter) Hegewald var. carinatus (Lemmermann) Hegewald, Algological Studies 96: 15. 2000 三 Scenedesmus opoliensis P. Richter var. carinatus Lemmermann, Forschungsberichte aus der Biologischen Station zu Plön 7: 113. 1899.

Figuras 68-70

Cenóbios planos, lineares, formados por 4 células; células elípticas a fusiformes, células externas com 1 espinho longo nos pólos, pólos agudos quase truncados, células internas com pólos arredondados, costelas dispostas em toda extensão celular ou fragmentadas, pequenos dentículos, 7,9$15,4 \times 2,0-4,7 \mu \mathrm{m}$, espinhos polares 9,0-27,0 $\mu \mathrm{m}$ compr.; cloroplastidio parietal, 1 pirenóide.

Hábitat: plâncton no Lago das Garças [Sant'Anna et al. 1989: 96, fig. 81, como Scenedesmus carinatus (Lemmermann) R. Chodat].

Conforme Chodat (1926), D. opoliensis (P. Richter) Hegewald var. carinatus (Lemmermann) Hegewald forma cenóbios muito semelhantes aos de D. opolienses (P. Richter) Hegewald var. opoliensis. Morfologicamente, ambos possuem o mesmo aspecto geral, com quatro células elíptico-fusiformes. Contudo, D. opoliensis (P. Richter) Hegewald var. carinatus (Lemmermann) Hegewald possui costelas que cortam todo o eixo longitudinal das células ou que podem aparecer fragmentadas, além da presença de dois ou três dentículos nos pólos celulares.

Desmodesmus opoliensis (P. Richter) Hegewald var. carinatus (Lemmermann) Hegewald é uma variedade que não possui muitas referências na literatura especializada nem é comum no Estado de 
São Paulo. A espécie mostrou variação morfológica com relação às dimensões celulares, ao tamanho dos espinhos e à presença ou ausência de pequenos espinhos polares nas células internas.

Desmodesmus opoliensis (P. Richter) Hegewald var. mononensis ( $\mathrm{R}$. Chodat) Hegewald, Algological Studies 96: 15. $2000 \equiv$ Scenedesmus opoliensis (P. Richter) Hegewald var. mononensis R. Chodat, Transactions of the Royal Society of South Africa 18: 31, fig. 6. 1929.

Figuras 71-73

Cenóbios planos, lineares, formados por 4 células; células elípticas a fusiformes, células externas com pólos agudos quase truncados, munidas de 1 espinho longo em cada pólo, espinhos das células externas situados excentricamente nos pólos celulares, células em contato por quase toda extensão celular, 7,0-14,9 $\times 2,0-5,6 \mu \mathrm{m}$, espinhos polares 3,0-18,0 $\mu \mathrm{m}$ compr.; cloroplastidio parietal, 1 pirenóide.

Hábitat: plâncton no Lago das Garças (SP399781, SP399782); primeira citação da ocorrência da variedade.

Segundo Hegewald \& Silva (1988), D. opoliensis (P. Richter) Hegewald var. mononensis (R. Chodat) Hegewald difere da variedade típica da espécie pelas células que se tocam em quase toda sua extensão e pelos cenóbios organizados mais ou menos em linha, além da presença de espinhos polares excêntricos.

Se, por um lado, a presente variedade taxonômica é de ocorrência comum nas águas do PEFI, por outro não tão fácil identificar seus representantes por serem muito parecidos com os da variedade típica da espécie. Colabora para essa dificuldade, os representantes da var. mononensis (R. Chodat) Hegewald apresentarem grande variação nas dimensões da célula, no tamanho dos espinhos e, às vezes, uma leve convexidade na parte mediana da margem externa da célula.

Desmodesmus pleiomorphus (Hindák) Hegewald, Algolgical Studies 16. $2000 \equiv$ Scenedesmus pleiomorphus Hindák, Archiv für Hydrobiologie, Suppl. 79: 482, fig. 19i. 1988.

Figuras 74-75

Cenóbios planos, lineares, formados por 4 células; células elípticas a cilíndricas, pólos arredondados, células externas com 1 espinho em cada pólo e 1 espinho na margem da célula externa, células internas com 1 espinho longo em cada pólo, 9,7-12,3 × 2,6-3,4 $\mu \mathrm{m}$, espinhos polares 5,0-12,0 $\mu \mathrm{m}$ compr.; cloroplastidio parietal, 1 pirenóide.
Hábitat: plâncton no Lago do IAG (SP399779, SP399780) e no Lago das Garças (SP399781, SP399782); primeira citação da ocorrência da espécie no Lago do IAG e no Lago das Garças.

Desmodesmus pleiomorphus

(Hindák)

Hegewald lembra, morfologicamente, D. spinosus R. Chodat, no entanto, difere por apresentar espinhos muito maiores nas células internas, o que é uma forte característica da espécie.

Há pouca informação disponível sobre $D$. pleiomorphus (Hindák) Hegewald devido à sua ocorrência pouco comum nos materiais até agora coletados. A espécie é universalmente considerada rara. Além disso, em todo o material ora examinado foram vistos somente espécimes com espinhos longos e destituídos de costelas.

Desmodesmus pleiomorphus (Hindák) Hegewald não apresentou variação morfológica significativa nas águas do PEFI e manteve sempre presente o caracter espinhos longos nos pólos das células internas.

* Desmodesmus protuberans (Fritsch \& Rich) Hegewald, Algological Studies 96: 16. 2000 三 Scenedesmus protuberans Fritsch \& Rich, Transactions of the Royal Society of South Africa 18: 31, fig. 6. 1929.

Figura 76

Cenóbios planos, lineares, formados por 4 células; células elípticas-fusiforme a fusiformes, pólos proeminentes, arredondados, células externas com margens convexas na parte mediana, células internas sem espinhos, 10,0-39,0 × 3,5-10,0 $\mu \mathrm{m}$, espinhos 8,0-20,0 $\mu \mathrm{m}$ compr.; cloroplastidio parietal, sem pirenóide.

Hábitat: plâncton no Lago das Garças (Sant'Anna et al. 1989: 97, fig. 91, como Scenedesmus protuberans Fritsch).

Conforme Comas (1996), esta espécie pode ser confundida com D. opoliensis (P. Richter) Hegewald, mas difere, basicamente, por seus pólos mais alargados, mais ou menos capitados, e pelos espinhos localizados aproximadamente no centro dos pólos celulares.

Desmodesmus protuberans (Fritsch \& Rich) Hegewald é uma espécie facilmente confundida com D. opoliensis (P. Richter) Hegewald e algumas de suas variedades; entretanto, D. protuberans (Fritsch \& Rich) Hegewald difere de D. opoliensis (P. Richter) Hegewald pelos pólos cônico-arredondados das células externas e pela ausência de espinhos polares nas células internas. Sant'Anna (1984) apontou 

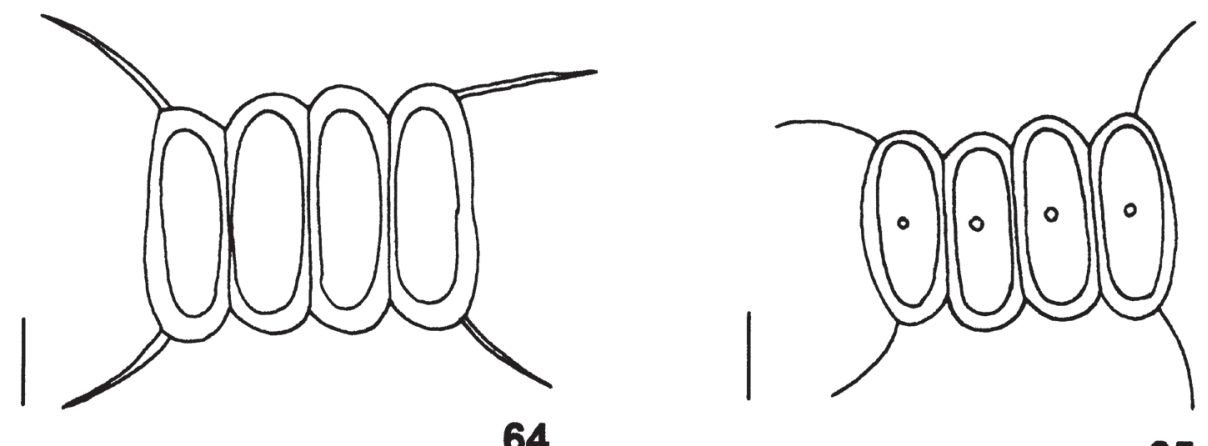

64

65

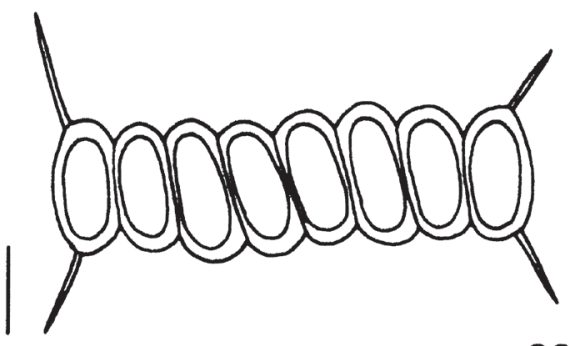

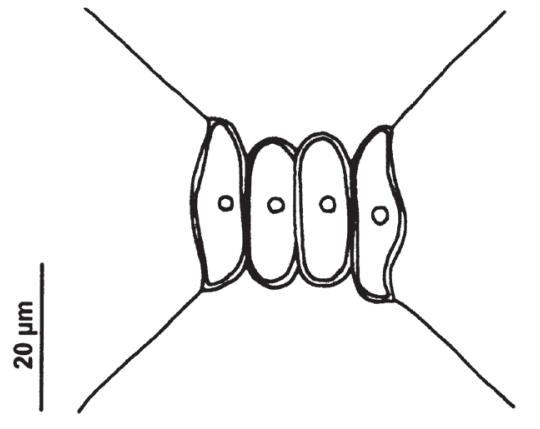

67

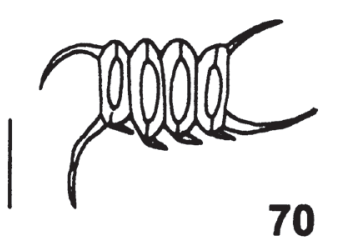

70

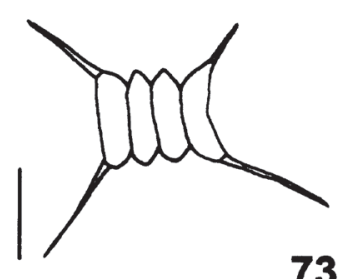

73

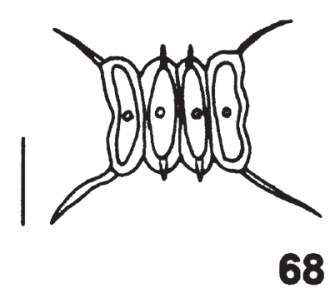

68

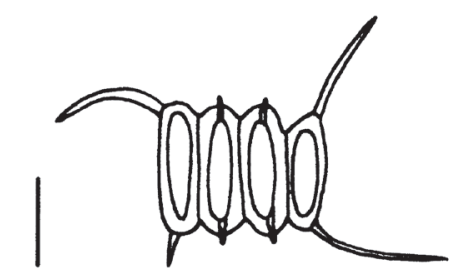

69
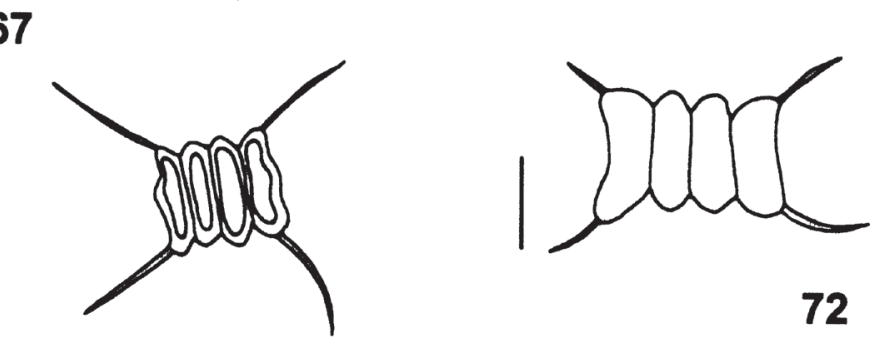

72

71

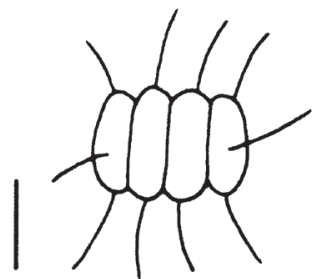

74

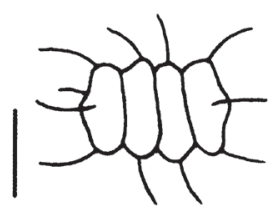

75

Figuras 64-75. Espécies de Scenedesmaceae do Parque Estadual das Fontes do Ipiranga. 64-66. Desmodesmus maximus. 67. Desmodesmus opoliensis var. opoliensis (conforme Sant'Anna 1984). 68-70. Desmodesmus opoliensis var. carinatus. 71-73. Desmodesmus opoliensis var. mononensis. 74-75. Desmodesmus pleiomorphus. Barras de escala $=10 \mu \mathrm{m}$, exceto quando especificamente indicado.

Figures 64-75. Species of Scenedesmaceae from the "Parque Estadual das Fontes do Ipiranga". 64-66. Desmodesmus maximus. 67. Desmodesmus opoliensis var. opoliensis (from Sant'Anna 1984). 68-70. Desmodesmus opoliensis var. carinatus. 71-73. Desmodesmus opoliensis var. mononensis. Desmodesmus pleiomorphus. Scale bars $=10 \mu \mathrm{m}$, except when especifically indicated. 
a configuração dos pólos como único caracter diferencial entre D. opoliensis (P. Richter) Hegewald e D. protuberans (Fritsch \& Rich) Hegewald, pois em D. opoliensis (P. Richter) Hegewald são excêntricos.

\section{Desmodesmus pseudodenticulatus (Hegewald)}

Hegewald, Algological Studies 96: 16. $2000 \equiv$ Scenedesmus pseudodenticulatus Hegewald in Hegewald \& Schnepf, Algological Studies 20: 312, 315, fig. 6-17. 1978.

Figuras 77-78

Cenóbios planos, lineares, formados por 4 células; células oblongas, pólos arredondados ou levemente truncados, células externas com pequenos espinhos, independentes, ligeiramente distante uns dos outros, na margem externa da célula, 1-2 espinhos nos pólos, células internas com 1-2 pequenos espinhos nos pólos, 12,0-13,8 × 3,7-5,5 $\mu \mathrm{m}$; cloroplastidio parietal, 1 pirenóide.

Hábitat: plâncton no Lago do IAG [SP399779; Ferragut et al. 2005: 154, fig. 83, como Desmodesmus pseudodenticulatus (Hegewald) Hegewald] e no Lago das Ninféias (SP399783).

Os espécimes examinados porFerragutetal.(2005) são muito parecidos com os do presente levantamento no que tange a margem externa das células externas com pequenos espinhos independentes, ligeiramente distantes uns dos outros, além da presença de um ou dois espinhos nos pólos e das células internas com um ou dois dentículos nos pólos.

Desmodesmus pseudodenticulatus (Hegewald) Hegewald tem a forma das células e os espinhos parecidos com os de D. lunatus (West \& West) Hegewald e D. spinulatus (Biswas) Hegewald, porém, difere destas duas espécies por apresentar células oblongas com pólos truncados.

* Desmodesmus serratus (Corda) An et al., Algological Studies 96: 17. $2000 \equiv$ Arthrodesmus serratus Corda, Almanach de Carlsbad 9: 244, pl. 6, fig. 35. 1839.

Figuras 79-82

Cenóbios planos, lineares, formados por 4 células; células elípticas a elíptico-fusiformes, pólos arredondados, células externas com pequenos espinhos individuais nas margens, membrana e espinhos unidos como em um pente ausentes, células internas com 1-2 espinhos pequenos nos pólos e costelas longitudinais na parte mediana da célula, costelas formadas pela união de espinhos muito pequenos, 7,3-21,3 × 2,1-7,9 $\mu \mathrm{m}$, espinhos polares 2,0-3,0 $\mu \mathrm{m}$ compr.; cloroplastidio parietal, 1 pirenóide.

Hábitat: plâncton no Lago das Garças [Sant'Anna et al. 1989: 97, fig. 95, como Scenedesmus serratus (Corda) Bohlin].

Chodat (1926) observou cenóbios com 4 células, como nos atuais exemplares, no entanto, Sant'Anna et al. (1989) observaram exemplares com apenas 2 células.

A espécie caracteriza-se pela fileira de dentículos em cada margem lateral, que vão longitudinalmente desde um dos pólos até o outro. No entanto, este caracter é muito variável e, às vezes, somente se observa ao microscópio óptico um dentículo em cada pólo, permitindo a confusão destes espécimes com os de outras espécies como, por exemplo, os de Scenedesmus brevispina (G. M. Smith) R. Chodat [= D. denticulatus (Lagerheim) An et al. var. linearis (Hansgirg) Hegewald de acordo com Hegewald (2000)].

Desmodesmus serratus (Corda) An et al. pode ser confundida com D. pseudodenticulatus (Hegewald) Hegewald, no entanto, a última não apresenta costelas. As duas espécies, contudo, possuem espinhos independentes em toda extensão da célula da margem externa, mas diferem quanto à forma das células: D. serratus (Corda) An et al. apresenta células elípticas a elíptico-fusiformes, com pólos arredondados e D. pseudodenticulatus (Hegewald) Hegewald apresenta células oblongas, com pólos arredondados e, às vezes, truncados. Pode também ser confundida com $D$. denticulatus (Lagerheim) An et al. var. linearis (Hansgirg) Hegewald e D. brasiliensis (Bohlin) Hegewald, mas é distinta por apresentar espinhos próximos na margem externa da célula, porém, independentes. Difere também pelas costelas em forma de dentículos que cortam toda a extensão da célula, um caracter que não ocorre em D. brasiliensis (Bohlin) Hegewald; e pela forma elíptico-fusiforme da célula.

Desmodesmus serratus (Corda) An et al. formou grandes populações, no entanto, a espécie é de difícil identificação, pois apresenta muita semelhança com várias outras do gênero. Deve-se tomar muito cuidado durante a identificação dos representantes desta espécie, pois a mesma apresentou variação morfológica significativa com relação à forma da célula, à ornamentação na parede celular, ao número de espinhos nos pólos celulares e à presença ou ausência de costelas. Foram atualmente vistos indivíduos absolutamente sem dentículos na margem 
externa da célula, razão pela qual reafirmarmos que D. serratus (Corda) An et al. é uma espécie muito variável e, consequentemente, de difícil identificação.

* Desmodesmus spinosus (R. Chodat) Hegewald, Algological Studies 96: 17. $2000 \equiv$ Scenedesmus spinosus R. Chodat, Monographie d'algues en culture pure. 74, fig. 70-74. 1913.

Figuras 83-84

Cenóbios planos, lineares, formados por 4 células; células elípticas a cilindricas, pólos arredondados, células externas com 1-2 espinhos em cada pólo, 1-2 espinhos quase do mesmo tamanho na margem da célula externa, células internas com 1 espinho em cada pólo, às vezes espinhos em toda parede celular, 9,7-12,3 × 2,6-3,4 $\mu \mathrm{m}$, espinhos polares 5,0-12,0 $\mu \mathrm{m}$ compr.; cloroplastidio parietal, 1 pirenóide.

Hábitat: plâncton no Lago das Garças (Moura 1996: 49, fig. 19, como Scenedesmus spinosus R. Chodat; Tucci 2002: 243, fig. 49, como Scenedesmus spinosus R. Chodat; Tucci et al. 2006: 165, fig. 52, como Scenedesmus spinosus R. Chodat) e no Lago do IAG [Ferragut et al.2005: 153, fig. 82, como Desmodesmus polyspinosus (Hortobágyi) Hegewald; Ferragut et al. 2005: 154, fig. 84-85, como Desmodesmus spinosus (R. Chodat) Hegewald var. spinosus].

Desmodesmus spinosus (R. Chodat) Hegewald é muito parecido com D. abundans (Kirchner) Hegewald, a ponto de alguns autores (exemplo Philipose 1967) considerarem a primeira espécie sinônimo da segunda. Sant'Anna (1984) não considerou D. spinosus (R. Chodat) Hegewald sinônimo de $S$. nanus R. Chodat após analisar toda a controvérsia em literatura e realizar um estudo comparativo dos caracteres usados na delimitação das duas espécies.

O caracter que diferencia $D$. spinosus (R. Chodat) Hegewald de D. abundans (Kirchner) Hegewald é a presença de dois espinhos de tamanhos desiguais entre si nas células externas. Às vezes, estes espinhos podem ocorrer isolados e, embora muito raro, também podem ocorrer em número de três. Em D. spinosus (R. Chodat) Hegewald, os espinhos marginais são praticamente do mesmo tamanho entre si e aparecem em maior número. Além disso, existem espinhos em toda a parede celular de todas as células do cenóbio. Outros caracteres diferenciais entre essas duas espécies são a forma das células, que em $D$. spinosus (R. Chodat) Hegewald é elíptico-cilíndrica e em $D$. abundans (Kirchner) Hegewald oblonga, e a presença de uma convexidade na margem externa das células extremas do cenóbio. O que dificulta a separação de D. spinosus (R. Chodat) Hegewald e D. abundans (Kirchner) Hegewald é que, às vezes, os espinhos podem não ser visíveis, como ocorreu com alguns exemplares atualmente examinados, dificultando a identificação de D. spinosus (R. Chodat) Hegewald.

Esta espécie também pode ser confundida com D. subspicatus (R. Chodat) Hegewald \& Schmidt, mas difere porque D. spinosus (Kirchner) Hegewald apresenta espinhos laterais e manifesta uma tendência à desagregação dos cenóbios em células solitárias e D. subspicatus (R. Chodat) Hegewald \& Schmidt carece de costelas e apresenta maior número (2-5) de espinhos laterais nas células marginais.

Ferragut et al. (2005) identificaram certos espécimes com D. polyspinosus (Hortobágyi) Hegewald, mas a análise da ilustração permitiu concluir que se trata de D. spinosus (R. Chodat) Hegewald. Tucci et al. (2006) identificaram Scenedesmus spinosus R. Chodat, contudo, os espécimes que estudaram diferem dos presentes pelo fato de apresentarem três espinhos nas margens das células externas, fato este pouco comum nos exemplares atualmente examinados.

Desmodesmus spinulatus (Biswas) Hegewald, Algological Studies 96: 17. 2000 三 Scenedesmus spinulatus Biswas, Hedwigia 74: 20. 1934.

Figuras 85-87

Cenóbios planos, lineares ou alternados, formados por 4 células; células elíptico-fusiformes, pólos truncados, células externas com 1-3 espinhos pequenos nos pólos, 1 espinho geralmente projetado perpendicularmente ao cenóbio, podendo ocorrer outros nas células internas, margens externas com espinhos pequenos independentes, células internas com 1-2 espinhos pequenos nos pólos, 10,0-16,2 $\times$ 3,0-3,7 $\mu \mathrm{m}$, espinhos polares 1,0-4,0 $\mu \mathrm{m}$ compr.; parede celular lisa ou com granulações, além das costelas que podem estar presentes ou ausente; cloroplastidio parietal, 1 pirenóide.

Hábitat: plâncton no Lago das Garças (SP399782); primeira citação da ocorrência da espécie.

Desmodesmus spinulatus (Biswas) Hegewald pode ser confundido com D. lunatus (West \& West) Hegewald, no entanto, difere porque o último possui células cilíndrico-fusiformes, com pólos truncados, além das células externas levemente arqueadas (lunadas). Também, as células externas e internas possuem 1-3 pequenos dentes. Desmodesmus spinulatus (Biswas) Hegewald também pode ser confundido 
com D. pseudodenticulatus (Hegewald) Hegewald, porém, a primeira espécie apresenta células elíptico-fusiformes e a segunda, células oblongas. Outra diferença está no fato da primeira espécie possuir um espinho geralmente projetado perpendicularmente ao cenóbio, que também pode ocorrer nas células internas, uma característica que não ocorre em $D$. pseudodenticulatus (Hegewald) Hegewald.

De acordo com Comas et al. (2007), existe muita semelhança morfológica entre as espécies atualmente incluídas em D. spinulatus (Biswas) Hegewald e Scenedesmus polydenticulatus Hortobágyi, mas nesta última os espinhos são robustos e lateralmente livres, além de estarem presentes também nas margens das células externas.

Desmodesmus spinulatus (Biswas) Hegewald apresentou variabilidade muito grande com relação à forma das células [alguns indivíduos apresentaram as células externas com uma concavidade no centro da margem e cenóbio alternado, muito parecido com D. denticulatus (Lagerheim) An et al. var. linearis (Hansgirg) Hegewald], à quantidade de espinhos nos pólos celulares e à ornamentação da parede celular.

\section{Pseudodidymocystis Hegewald \& Deason}

Indivíduos coloniais de vida livre. O cenóbio é formado apenas por duas células que se dispõem uma ao lado da outra segundo seus eixos mais longos. Uma matriz mucilaginosa relativamente abundante envolve o cenóbio. As células são elipsóides a semicirculares. A parede celular apresenta ornamentação na forma de material inorgânico granular ou verrucoso. Cloroplastídio parietal, com ou sem pirenóide.

Chave para identificação das espécies de Pseudodidymocystis

1. Parede celular lisa P. fina

1. Parede celular ornamentada P. planctonica

Pseudodidymocystis fina (Komárek) Hegewald \& Deason, Algological Studies 55: 127. $1989 \equiv$ Didymocystis fina Komárek, Preslia 47: 276, fig. 3. 1975.

Figura 88

Cenóbios planos, lineares, formados por 2 células; células oblongas, margens externas convexas ou quase retas, 5,2-10,2 × 2,3-4,1 $\mu \mathrm{m}$; parede celular lisa; cloroplastidio parietal, sem pirenóide.

Hábitat: plâncton no Lago do IAG (SP399779; Ferragut et al. 2005: 154, fig. 87, como Didymocystis fina Komárek), no Lago das Ninféias (SP399783) e no Lago das Garças [Tucci 2002: 243, fig. 41, como Pseudodidymocystis fina (Komárek) Hegewald \& Deason; Tucci et al. 2006: 163, fig. 46, como Pseudodidymocystis fina (Komárek) Hegewald \& Deason].

Segundo Hegewald \& Deason (1989), Didymocystis fina Komárek foi descrita sem pirenóide nem mucilagem, no entanto, existe uma camada de mucilagem cuja espessura é menor do que $1 \mu \mathrm{m}$ e, talvez por isso, seja facilmente negligenciada. $\mathrm{O}$ pirenóide também, segundo os mesmos autores, nem sempre é visível. Heynig \& Krienitz (1987), Heynig (1989) e Hegewald \& Deason (1989) observaram, entretanto, pirenóides em materiais coletados na Europa considerados idênticos a Pseudodidymocystis fina (Komárek) Hegewald \& Deason.

Tucci et al. (2006) examinaram espécimes do PEFI que apresentaram células alongadas, com parede lisa, dispostas paralelamente umas às outras em relação ao seu eixo longitudinal, semelhantes aos indivíduos do presente levantamento, exceto pelas dimensões, pois os atuais espécimes foram consistentemente um pouco maiores.

Pseudodidymocystis planctonica (Koršikov) Hegewald \& Deason, Algological Studies 55: 127. $1989 \equiv$ Didymocystis planctonica Koršikov, Viznačnik prisnovodnich vodorostej Ukrainskoj RSR 5: 396, fig. 399. 1953.

\section{Figura 89}

Cenóbios planos, lineares, formados por 2 células; células oblongas, margens externas convexas ou quase retas, $8,0-13,4 \times 3,8-5,5 \mu \mathrm{m}$; parede celular lisa, às vezes granulosa, cloroplastídio parietal, 1 pirenóide.

Hábitat: plâncton no Lago do IAG (SP399780) e no Lago das Garças [Moura 1996: 46, fig. 6, como Didymocystis planctonica Koršikov; Tucci 2002: 243, fig. 40; Tucci et al. 2006: fig. 47, como Pseudodidymocystis planctonica (Koršikov) Hegewald \& Deason].

Hegewald \& Deason (1989) identificaram Pseudodidymocystis planctonica (Koršikov) Hegewald \& Deason por suas células apresentarem uma fina estrutura típica das células de Scenedesmus, no entanto, incluindo um pirenóide simples cercado por amido e com três camadas de esporopolenina na parede celular.

Os exemplares presentemente observados concordam com aqueles em Tucci et al. (2006), 


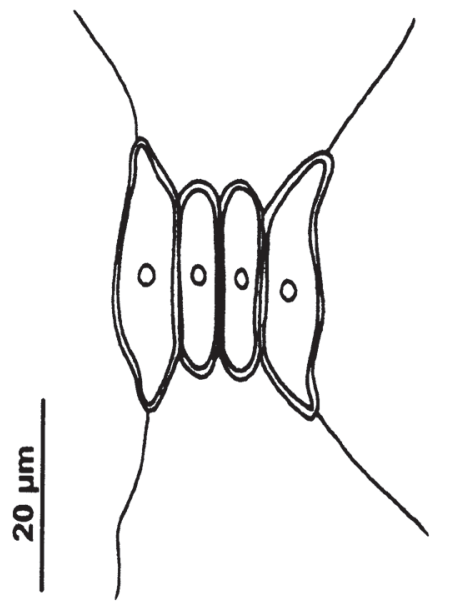

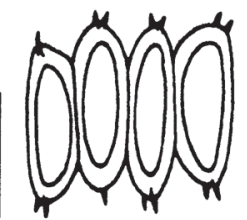

77

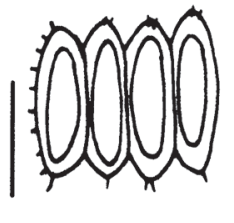

78

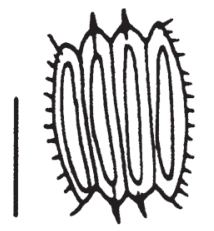

79

76

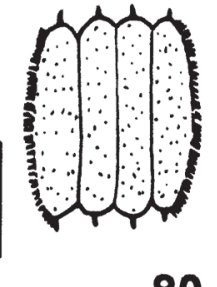

80

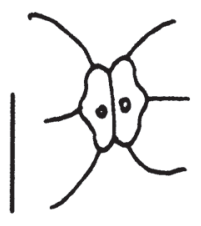

84

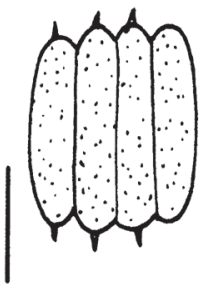

81

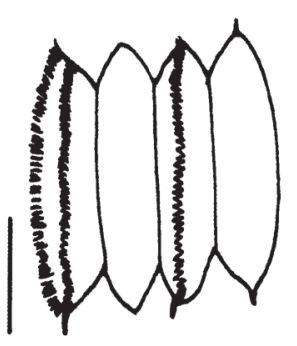

82

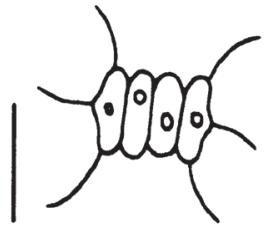

83

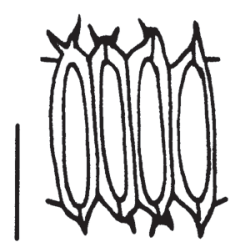

85

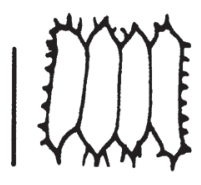

86

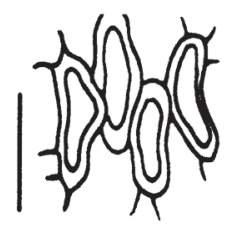

87

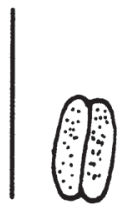

88

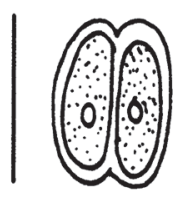

89

Figuras 76-89. Espécies de Scenedesmaceae do Parque Estadual das Fontes do Ipiranga. 76. Desmodesmus protuberans (conforme Sant'Anna 1984). 77-78. Desmodesmus pseudodenticulatus. 79-82. Desmodesmus serratus. 83-84. Desmodesmus spinosus (conforme Ferragut et al. 2005). 85-87. Desmodesmus spinulatus. 88. Pseudodidymocystis fina (conforme Ferragut etal. 2005). 89. Pseudodidymocystis planctonica (conforme Tucci et al. 2006). Barras de escala $=10 \mu \mathrm{m}$, exceto quando especificamente indicado.

Figures 76-89. Species of Scenedesmaceae from the "Parque Estadual das Fontes do Ipiranga". 76. Desmodesmus protuberans (from Sant'Anna 1984). 77-78. Desmodesmus pseudodenticulatus. 79-82. Desmodesmus serratus. 83-84. Desmodesmus spinosus (from Ferragut et al. 2005). 85-87. Desmodesmus spinulatus. 88. Pseudodidymocystis fina (from Ferragut et al. 2005). 89. Pseudodidymocystis planctonica (from Tucci et al. 2006). Scale bars $=10 \mu \mathrm{m}$, except when especifically indicated. 
que apresentaram cenóbios 2-celulados, estando as células oblongas dispostas paralelas uma à outra em relação ao eixo longitudinal; no entanto, os atuais espécimes foram um pouco maiores.

As populações examinadas foram sempre constituídas por poucos indivíduos e a variação morfológica referiu-se, somente, às dimensões celulares.

\section{SUBFAMÍLIA SCENEDESMOIDEAE}

Cenóbios planos, lineares, raramente semicirculares ou com suas células mais ou menos cruzadas; células cilíndricas, ovais, fusiformes, unidas em paralelo em cenóbios de 1 ou 2 fileiras, com seus eixos longitudinais mais ou menos perpendiculares ao plano do cenóbio, às vezes formando tétradas unidas por suas margens convexas; cloroplastídio parietal, com ou sem pirenóide; parede celular lisa ou com verrugas, dentículos, espinhos ou costelas. Em algumas espécies, formam-se estruturas semelhantes a pregas na parede celular; reprodução exclusivamente por autósporos, que são liberados pelo rompimento da parede da célula-mãe.

\section{Scenedesmus Meyen}

Este gênero incluía, inicialmente, todas as algas verdes cocóides, autospóricas, que formavam cenóbios mais ou menos lineares, planos ou curvos. Smith (1916) publicou a primeira monografía baseada em cultivos das espécies de Estados Unidos da América e Chodat (1926), também a partir de material cultivado, publicou a monografía das espécies da Suíça. Outro compilado regional, para Hungria, é o de Uherkovich (1966). Komárek \& Fott (1983) fizeram uma revisão mundial das espécies do gênero. Saliente-se, finalmente, o catálogo publicado por Hegewald \& Silva (1988), que inclui cerca de 1.300 táxons descritos.

Chodat (1926) estabeleceu um sistema de subgêneros que refletiam as relações taxonômicas entre os numerosos táxons descritos. Hegewald (1978) reduziu o número desses subgêneros a três: Scenedesmus, Acutodesmus Hegewald e Desmodesmus R. Chodat. Este sistema foi aceito por Komárek \& Fott (1983).

An et al. (1999) concluíram que tanto com base na ultra-estrutura quanto na genética molecular o gênero Scenedesmus pode ser dividido em dois outros, independentes, que são: Scenedesmus 'sensu stricto', cuja parede celular é composta por três camadas de esporopolenina e destituída de ornamentação e Desmodesmus, cuja parede celular é formada por quatro camadas de esporopolenina e possui ornamentação formada em sua camada mais externa. No entanto, dada à falta de critérios moleculares mais sólidos, o subgênero Acutodesmus (incl. Tetradesmus) foi elevado a gênero (Tsarenko \& Petlevanny 2001).

No final da década de 80 do século passado, se observa na literatura taxonômica sobre Scenedesmus uma tendencia à concepção de espécies em um sentido amplo (Comas 1996), como foi o caso de S. obtusus Meyen, com uma extensa lista de sinônimos isotípicos e heterotípicos (Hegewald et al. 1988, Hindák 1990). Mas, sobre bases genético-moleculares separaram-se espécies em um sentido mais restrito (Hegewald \& Hanagata 2000).

Scenedesmus inclui hoje indivíduos coloniais em que os cenóbios podem ser planos ou alternados, formados por 2-16 células (raro 32) cujos eixos mais longos são paralelos entre si. A disposição destes cenóbios pode ser em uma ou duas séries. As células podem ser elipsóides, ovóides, fusiformes ou lunadas e podem ser todas iguais no mesmo cenóbio ou as células externas de uma forma e as internas de outra. Os pólos podem ser amplamente arredondados ou atenuados, truncados, até pontiagudos. A parede celular é lisa na maioria das espécies, mas também pode ser ornada com pequenas verrugas. Reprodução por 2-8 ou mais autósporos que formam um só autocenóbio dentro da célula materna, liberandose por rompimento da parede da célula-mãe. Cloroplastídio parietal, com um pirenóide.

Chave para identificação dos subgêneros de Scenedesmus

1. Células com os pólos mais ou menos agudos subgênero Acutodesmus

1. Células com os pólos arredondados e destituídos de espinhos subgênero Scenedesmus

\section{Subgênero Acutodesmus}

O subgênero Acutodesmus Hegewald compreende as espécies do gênero Scenedesmus que possuem células fusiformes ou elíptico-fusiformes, com os pólos mais ou menos agudos. A parede celular é destituída de ornamentação ou estruturas. Scenedesmus acutiformis Schröder possui estruturas semelhantes a costelas na parede celular produzidas por pregas situadas nas camadas mais externas da parede e foi, por isso, transferida para o gênero 
Enallax (Hindák 1990, Hegewald \& Hanagata 2000). As espécies neste subgênero apresentam ampla variabilidade morfológica, tanto na forma das células quanto dos cenóbios (alinhados ou alternados, em uma ou duas fileiras), fato este que vem provocando, como conseqüência, a descrição e proposição de numerosas espécies, variedades e formas taxonômicas. Está provado que existem tanto populações intermediárias quanto indivíduos intermediários dentro de uma mesma espécie, comprovando-se a influência dos fatores externos sobre os caracteres morfológicos, favorecendo a aparição de determinados morfotipos (Holtmann \& Hegewald 1986, Mladenov \& Furnadžieva 1999, Belkinova \& Mladenov 2000, 2002). As espécies geralmente aceitas estão, ainda, também sujeitas aos critérios de diferentes autores (Hegewald 1979, Ooshima 1981, Komárek \& Fott 1983, Comas \& Komárek 1984, Krienitz 1987, Hindák 1990).

Tsarenko em Tsarenko \& Petlevanny (2001) elevou o subgênero Acutodesmus à categoria de gênero e efetuou as mudanças nomenclaturais devidas de algumas espécies anteriormente classificadas em

\section{Scenedesmus.}

Hegewald \& Wolf (2003) confirmaram, através de estudos de sequências gênicas utilizando como marcadores genéticos 18S rDNA e de ITS-2, que as relações entre Scenedesmus e Acutodesmus não estão ainda totalmente esclarecidas, especialmente no ramo formado por $A$. pectinatus (Meyen) Tsarenko, A. regularis (Svirenko) Tsarenko e $S$. arcuatus Lemmermann, espécies estas relacionadas filogeneticamente, porém, separadas de outras espécies porque os referidos autores (Hegewald \& Wolf 2003) localizaram este grupo de espécies em "Scenedesmaceae incertae sedis" não confirmando, portanto, o gênero Acutodesmus no sentido de Tsarenko \& Petlevanny (2001).

De acordo com os critérios acima, a diferença entre Scenedesmus e Acutodesmus reside atualmente em bases morfológicas e nem todas as espécies morfologicamente similares a Acutodesmus foram estudadas (exemplo $S$. incrassatulus Bohlin, $S$. bourrellyi Iltis, $S$. ginzbergeri Kammer, etc.). Preferimos, por isso, considerar Acutodesmus no nível de subgênero.

Chave para identificação das espécies e variedades do subgênero Acutodesmus

1. Cenóbios com células dispostas em 1 série (lineares)

2. Pólos celulares pontiagudos

S. regularis

2. Pólos celulares acuminados

3. Pólos celulares afilados gradualmente para a extremidade

3. Pólos celulares afilados abruptamente para a extremidade

1. Cenóbios com células dispostas em 2 séries (alternados)

4. Células arranjadas em mais de 1 plano do espaço

4. Células arranjadas em 1 só plano do espaço

5. Pólos celulares capitados S. indicus

5. Pólos celulares não capitados

6. Pólos celulares acuminados

6. Pólos celulares pontiagudos

7. Células fusiformes retas

S. acuminatus var. acuminatus p.p. S. obliquus var. dimorphus p.p.

7. Células fusiformes curvadas

8. Comprimento da célula 23,7-29,1 $\mu \mathrm{m}$, largura 3,6-4 $\mu \mathrm{m}$

8. Comprimento da célula 39,0-50,0 $\mu \mathrm{m}$, largura 7,0-8,0 $\mu \mathrm{m}$

S. acuminatus var. elongatus

8. Comprimento da célula $39,0-50,0 \mu \mathrm{m}$, largura $7,0-8,0 \mu \mathrm{m}$ ... S. acuminatus var. acuminatus p.p. .. S. obliquus var. dimorphus p.p. S. javanensis var. javanensis S. javanensis var. schroeteri

* Scenedesmus acuminatus (Lagerheim) R. Chodat var. acuminatus, Algues vertes de Suisse. 211. $1902 \equiv$ Selenastrum acuminatum Lagerheim, Öfversigt af Kungliga Vetenskapsakademiens förhandlingar 39(2): 71, pl. 3, fig. 27-30. 1882.

Figuras 90-91

Cenóbios planos, lineares ou alternados, formados por 4-8 células; células fusiformes, lunadas, acuminadas, pólos acuminados, células externas marcadamente arqueadas, células internas quase retas, 20,4-34,1 × 3,0-5,4 $\mu \mathrm{m}$; cloroplastídio parietal, 1 pirenóide.

Hábitat: plâncton no Lago das Garças [Sant'Anna et al. 1989: 95, fig. 65-66, como Scenedesmus 
acuminatus (Lagerheim) R. Chodat] e no Lago do IAG [Ferragut et al. 2005: 155, fig. 88, como Scenedesmus acuminatus (Lagerheim) R. Chodat var. acuminatus].

Scenedesmus acuminatus (Lagerheim) R. Chodat é, segundo Nogueira (1991), uma espécie que apresenta inúmeras expressões morfológicas descritas como várias categorias taxonômicas, no que está certa, pois esta é uma espécie muito variável morfologicamente e que inclui, conforme Comas (1996), numerosos táxons de níveis infra-específicos. É absolutamente necessário providenciar uma análise de população e, paralelamente, a comparação com a diagnose e/ou descrição original desta espécie e de outras afim para maiores esclarecimentos sobre esta espécie.

Deve-se ter cautela quando identificar $S$. acuminatus (Lagerheim) R. Chodat devido à semelhança com morfotipos de $S$. obliquus (Turpin) Kutzing var. dimorphus (Turpin) Kutzing. Cenóbios dispostos linear ou alternadamente, células fusiformes ou lunadas, com pólos acuminados são as características diagnósticas da espécie. Variação morfológica foi observada somente em relação à forma das células, que ora foi mais arqueada (com uma concavidade maior) ora menos arqueada. Conclui-se, consequentemente, que foram registrados espécimes de Scenedesmus acuminatus (Lagerheim) R. Chodat dos tipo 'pectinatus' e 'dimorphus'.

* Scenedesmus acuminatus (Lagerheim) R. Chodat var. elongatus G.M. Smith, Transactions of the American Microscopical Society 45: 189, pl. 16, fig. 13-15. 1926.

Figura 92

Cenóbios nem sempre dispostos no mesmo plano, formados por 4 células; células dispostas irregularmente, torcidas, lunadas, pólos acuminados, células formando um arranjo particular, mais ou menos estrelado, $30,0-40,0 \times 3,0-5,5 \mu \mathrm{m}$; cloroplastídio parietal, 1 pirenóide.

Hábitat: plâncton no Lago das Garças [Sant'Anna et al. 1989: 96, fig. 67, como Scenedesmus acuminatus (Lagerheim) R. Chodat var. elongatus G.M. Smith].

Conforme Sant'Anna (1984), S. acuminatus (Lagerheim) R. Chodat var. elongatus G.M. Smith difere da variedade típica da espécie pelas células irregularmente torcidas, que formam uma placa curva, com arranjo mais ou menos estrelado das células.

* Scenedesmus indicus Philipose ex Hegewald,
Engelberg \& Paschma, Nova Hedwigia 47(3-4): 515, fig. 167. 1988 [= Scenedesmus productocapitatus Schmula var. indicus (Philipose)

Hegewald, 1976 nomen invalidum].

Figura 93

Cenóbios planos, alternados, formados por 4 células; células lunadas, espessamento nos ápices, como uma coroa, células externas marcadamente côncavas, células internas tocando-se pelos pólos, sub-apicalmente, $12,5-13,0 \times 3,5-5,0 \mu \mathrm{m}$; cloroplastídio parietal, 1 pirenóide.

Hábitat: plâncton no Lago das Garças (Tucci 2002: 243, fig. 48; Tucci et al. 2006: 163, fig. 49; como Scenedesmus indicus Philipose).

Conforme Hegewald \& Silva (1988), S. indicus Philipose ex Hegewald et al. possui cenóbios constituídos por 4 células curvadas, com espessamento nos ápices na forma de uma coroa e relativamente bem largas na parte mediana. Essas células estão organizadas em uma série alternada, com os pólos das células internas em contato com a parte mediana da célula externa e o final da parte interna quase todo livre. Tucci et al. (2006) observou, entretanto, exemplares que formavam cenóbios com quatro células lunadas, dispostas em série alternada e possuíam espessamento nos ápices das células.

Scenedesmus javanensis R. Chodat var. javanensis, Zeitschrif für Hydrologie 3: 157, fig. 47. 1926. Figura 94

Cenóbios planos, alternados, formado por 4 células; células lunadas, assimétricas, pólos acuminados, células externas marcadamente côncavas, células internas assimétricas, o pólo de uma célula tocando a parte subapical da outra célula, 23,729,1 × 3,6-4,0 $\mu \mathrm{m}$; cloroplastidio parietal, 1 pirenóide. Hábitat: plâncton no Lago das Garças [SP399782; Sant'Anna et al. 1989: 96, fig. 71, como Scenedesmus acuminatus (Lagerheim) R. Chodat var. bernadii (G.M. Smith) Dedusenko].

Foram encontrados representantes desta espécie somente no Lago das Garças, mas, sempre formando populações constituídas por numerosos indivíduos. Além disto, é considerada uma espécie de fácil identificação devido aos seus cenóbios alternados, formados por células lunadas, assimétricas, de pólos acuminados. As células externas são marcadamente côncavas e as internas assimétricas, além de estarem em contato com a célula adjacente só na parte subapical. Variação morfológica foi notada apenas nas dimensões celulares. 
* Scenedesmus javanensis R. Chodat var. schroeteri (Huber-Pestalozzi) Comas \& Komárek in Toledo \& Comas, Acta Botánica Cubana 57: 7, fig. 5. 1988.

Figura 95

Cenóbios planos, alternados, formados por 4 células; células lunadas, assimétricas, pólos acuminados, células externas marcadamente côncavas, células internas assimétricas, o pólo de uma célula tocando a parte subapical da célula adjacente, 39,0-50,0 ×7,0-8,0 $\mu \mathrm{m}$; cloroplastídio parietal, 1 pirenóide.

Hábitat: plâncton no Lago das Garças [Sant'Anna et al. 1989: 96, fig. 70, como Scenedesmus acuminatus (Lagerheim) R. Chodat f. maximus Uherkovich].

Scenedesmus javanensis R. Chodat var. schroeteri (Huber-Pestalozzi) Comas \& Komárek difere da variedade-tipo da espécie por apresentar dimensões das células muito maiores.

\section{Scenedesmus obliquus (Turpin) Kutzing var.} dimorphus (Turpin) Hansgirg, Archiv der naturwissenschaft Landesdurchf. von Böhmen 6(5): 116. 1888. $\equiv$ Achnanthes dimorphus Turpin, Mémoires du Museu national d'Histoire naturelle 16: 313, pl. 13, fig. 12, 1828.

Figuras 96-105

Cenóbios planos, lineares ou alternados, formados por 4-8 células; células fusiformes a oval-fusiformes, pólos agudos, células externas marcadamente côncavas até retas ou levemente convexas, células internas quase retas, 6,5-31,0 × 1,9-6,7 $\mu \mathrm{m}$; cloroplastídio parietal, 1 pirenóide.

Hábitat: plâncton no Lago das Garças (SP399781, SP399782; Sant'Anna et al. 1989: 96, fig. 72, como Scenedesmus acutus Meyen; Sant'Anna et al. 1989: 96, fig. 73, como Scenedesmus acutus Meyen var. acutus f. alternans Hortobágyi), no Lago das Ninféias (SP399783; Schetty 1998: 12, fig. 31, como Scenedesmus acutus Meyen var. acutus f. acutus) e no Lago do IAG [Ferragut et al. 2005: 155, fig. 89, como Scenedesmus acutus Meyen var. acutus f. acutus; 155, fig. 90, como Scenedesmus acutus Meyen var. acutus f. alternans Hortobágyi; 155, fig. 92, como Scenedesmus dimorphus (Turpin) Kützing; 155, fig. 96, como Scenedesmus obliquus (Turpin) Kützing].

Scenedesmus obliquus (Turpin) Kützing pertence a um dos grupos de espécies de identificação mais complicada do subgênero Acutodesmus devido à sua ampla variabilidade morfológica. Os três tipos morfológicos principais que têm servido para estabelecimento de espécies ou variedades de Acutodesmus são: (1) cenóbios formados por células amplamente fusiformes ou fusiforme-elípticas, mais ou menos retas, pólos acuminado-arredondados, células distribuídas alternadamente em uma ou duas fileiras (tipo S. obliquus); (2) cenóbios formados por células desde estreitamente até amplamente fusiformes, células externas nitidamente lunadas ou com uma convexidade na margem externa que não sobrepõe a linha dos pólos, pólos pontiagudos, células alinhadas ou levemente alternadas em uma fileira (tipo S. dimorphus); e (3) cenóbios formados por células amplamente fusiformes, células externas levemente curvas, voltadas para fora (ao menos seus extremos), margens livres com uma convexidade que geralmente sobrepassa a linha dos pólos, pólos mais ou menos pontiagudos, células alinhadas ou levemente alternadas, geralmente em uma, raro em duas fileiras (tipo $S$. acutus). Dentro de cada um desses morfotipos são encontradas modificações diferentes e particulares que deram origem a numerosos táxons infra-específicos (Hegewald \& Silva 1988).

Pode-se interpretar Scenedesmus acuminatus (Lagerheim) R. Chodat 'sensu lato' como claramente constituído por dois morfotipos, acuminatus e pectinatus, sem populações intermediárias, que taxonomicamente constituiriam uma só espécie, $S$. obliquus (Turpin) Kützing, que incluiria $S$. acutus Meyen e $S$. dimorphus Turpin, como fizeram autores como Hegewald $(1979,1989)$ e Holtmann \& Hegewald (1986) e não três espécies independentes uma da outra, como fez Komárek \& Fott (1983). Aceitamos os critérios de Toledo \& Comas (1988) e Comas (1996), quando consideraram duas variedades taxonômicas: S. obliquus (Turpin) Kützing var. obliquus e S. obliquus (Turpin) Kützing var. dimorphus (Turpin) Kützing (incluindo S. acutus Meyen).

Scenedesmus obliquus (Turpin) Kutzing var. dimorphus (Turpin) Kutzing é a espécie que apresenta a maior variabilidade morfológica dentro do gênero, o que levou a definir a espécie como de identificação relativamente complicada pelo fato de apresentar vários tipos morfológicos, além de inúmeras populações intermediárias.

* Scenedesmus regularis Svirenko, Russkiî arkhiv protistologii 3(1-2): 178, fig. II: 11. 1924.

Figura 106

Cenóbios planos, lineares, formados por 4 células; células fusiformes, delgadas, unidas 


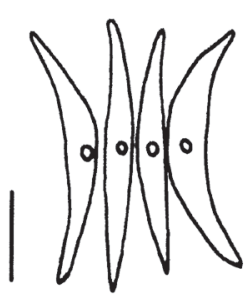

90

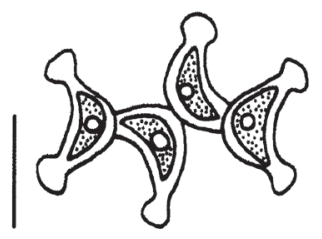

93

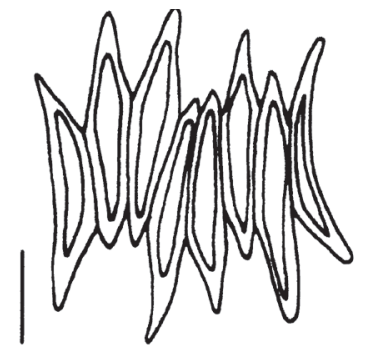

91

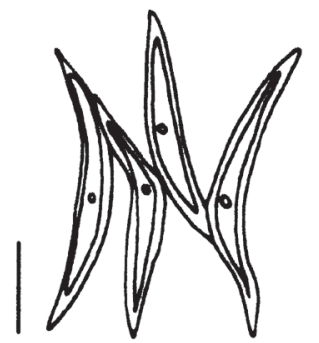

94

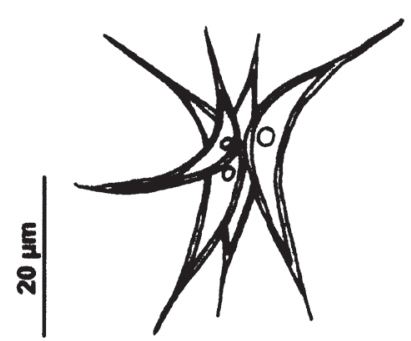

92

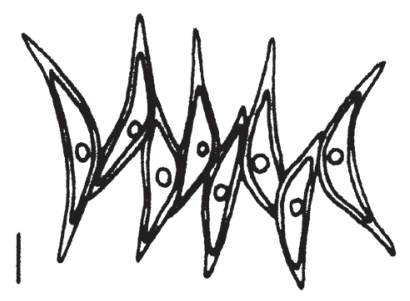

95

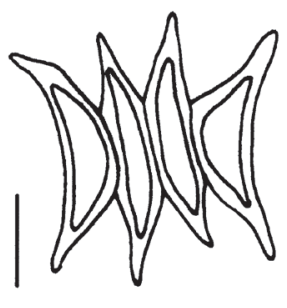

96

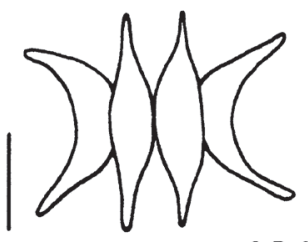

101

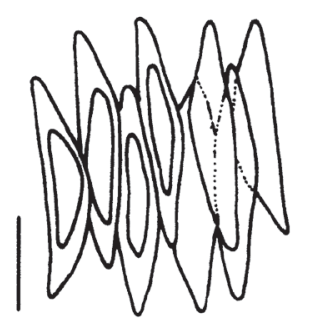

104

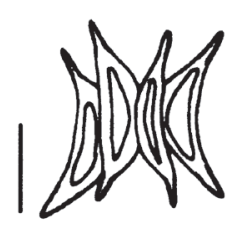

97

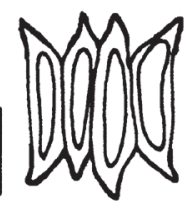

98

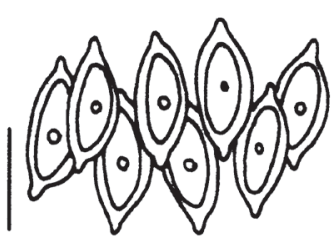

102

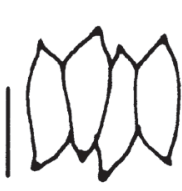

99

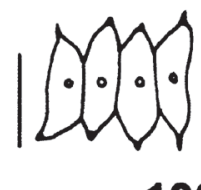

100

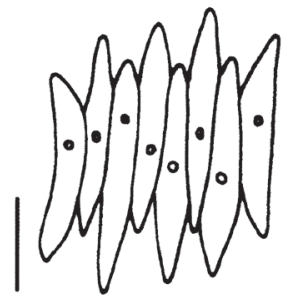

103

104

Figuras 90-106. Espécies de Scenedesmaceae do Parque Estadual das Fontes do Ipiranga. 90-91. Scenedesmus acuminatus var. acuminatus. 92. Scenedesmus acuminatus var. elongatus (conforme Sant'Anna 1984). 93. Scenedesmus indicus (conforme Tucci et al. 2006). 94 Scenedesmus javanensis. 95. Scenedesmus javanensis var. schroeteri (conforme Sant'Anna et al. 1989). 96-105. Scenedesmus obliquus var. dimorphus. 106. Scenedesmus regularis (conforme Tucci et al. 2006). Barras de escala $=10 \mu$ m, exceto quando especificamente indicado.

Figures 90-106. Species of Scenedesmaceae from the "Parque Estadual das Fontes do Ipiranga". 90-91. Scenedesmus acuminatus var. acuminatus. 92. Scenedesmus acuminatus var. elongatus (from Sant'Anna 1984). 93. Scenedesmus indicus (from Tucci et al. 2006 ). 94. Scenedesmus javanensis. 95. Scenedesmus javanensis var. schroeteri (from Sant'Anna et al. 1989). 96-105. Scenedesmus obliquus var. dimorphus. 106. Scenedesmus regularis (from Tucci et al. 2006). Scale bars $=10 \mu \mathrm{m}$, except when especifically indicated. 
na região mediana, polós atenuados, curvos nas células externas voltados para o interior do cenóbio, praticamente retos nas células internas, 12,0-15,0 $\times$ 2,5-4,0 $\mu \mathrm{m}$; cloroplastidio parietal, 1 pirenóide.

Hábitat: plâncton no Lago das Garças (Tucci 2002: 243, fig. 47; Tucci et al. 2006: 165, fig. 50; como Scenedesmus regularis Svirenko).

Scenedesmus regularis Svirenko lembra $S$. obliquus (Turpin) Kützing var. dimorphus (Turpin) Kützing e $S$. pectinatus (Meyen) Tsarenko graças à forma de suas células. Estudos genéticos moleculares confirmaram o parentesco de $S$. regularis Svirenko com $S$. pectinatus (Meyen) Tsarenko e com $S$. arcuatus (Lemmermann) Lemmermann, sendo inserida por Hegewald \& Wolf (2003) em Scenedesmaceae "incertae sedis".

Tucci (2002) e Tucci et al. (2006) identificaram material do PEFI com $S$. regularis Svirenko, com o que presentemente concordamos, pois ambos os materiais concordam com a figura original da espécie em Hegewald \& Silva (1988: fig. 771).

\section{Subgênero Scenedesmus}

O subgênero comprende as espécies que têm pólos arredondados e sem espinhos e a camada externa da parede celular constituída por esporopolenina. A decoração da parede pode ser por grânulos ou verrugas produzidas por impregnações de ferro e manganês. Essas espécies caracterizam-se também por constituírem cenóbios de formas variadas desde alinhados em série a leve ou acentuadamente alternados e até disciformes, em que as células aparecem espacialmente ordenadas em um plano. Estas características são tradicionalmente utilizadas para diferenciar espécies ou níveis infra-específicos.

A taxonomia deste grupo encontra-se atualmente em boa condição, embora a maioria das espécies nele contida apresente ampla variabilidade de seus caracteres diagnósticos que levaram à descrição de numerosos táxons, inclusive com a repetição de epíteto específico como disciformis, flexuosus, platydiscus, etc., complicando bastante a taxonomia dos táxons neste grupo. Komárek \& Fott (1983) colocaram ordem em uma complicada amplitude nomenclatural, embora Hegewald et al. (1988), a última monografia publicada sobre este grupo, se contraponha a muitas das soluções propostas em Komárek \& Fott (1983).

Estes novos critérios baseiam-se, muitas vezes, em novas interpretações de espécies ou na designação de tipos nomenclaturais. De maneira geral, são concebidas espécies muito amplas, como no caso de $S$. obtusus Meyen e $S$. arcuatus (Lemmermann) Lemmermann. Os mesmos critérios usados para identificar essas duas espécies encontram-se também utilizados por Hindák (1990).

A genética molecular constitui excelente base para separar Scenedesmus de Desmodesmus (An et al. 1999). Mas, também vem mostrando relações filogenéticas surpreendentes como a proximidade de $S$. arcuatus (Lemmermann) Lemmermann com $S$. regularis Svirenko e S. pectinatus (Meyen) Tsarenko, grupo este considerado Scenedesmaceae 'incertae sedis' (Hegewald \& Wolf 2003).

Chave para identificação das espécies e variedades do subgênero Scenedesmus

1. Cenóbios com células dispostas em 1 série apenas

2. Cenóbios 2-celulados

3. Pirenóide presente S. ecornis p.p.

3. Pirenóide ausente S. bicellularis

2. Cenóbios 4-celulados

4. Células dispostas alternando uma mais para cima e outra mais para baixo S. acunae p.p.

4. Células dispostas sem alternar uma mais para cima e outra mais para baixo

5. Células oblongas S. ecornis p.p.

5. Células oval-cilíndricas, elípticas a elíptico-cilíndricas

6. Células oval-cilíndricas S. obtusus p.p.

6. Células elípticas a elíptico-cilíndricas

7. Células com espessamento nos pólos S. acunae p.p.

7. Células sem espessamento nos pólos S. ellipticus

1. Cenóbios com células dispostas em 2 séries sobrepostas.

8. Parede celular com verrugas, principalmente, nos pólos S. verrucosus 


\section{Parede celular sem verrugas}

9. Células com espaços intercelulares S. arcuatus var. platydiscus

9. Células sem espaços intercelulares S. obtusus p.p.

Scenedesmus acunae Comas, Acta Botánica Cubana 2: 7-8, fig. 7d-f. 1980.

Figuras 107-109

Cenóbios planos, lineares, raro alternados, formados por 4-8 células; células elípticas, pólos arredondados, células externas marcadamente convexas, células internas retas, células externas e internas podendo apresentar espessamento da parede celular, espinhos ausentes em todas as células do cenóbio, 5,0-18,4 × 2,0-6,1 $\mu \mathrm{m}$; cloroplastidio parietal, 1 pirenóide.

Hábitat: plâncton no Lago do IAG (SP399779, SP399780), no Lago das Garças (SP399781) e no Lago das Ninféias (SP399783); primeira citação da ocorrência da espécie nos três lagos.

Scenedesmus acunae Comas pode ser confundida com $S$. ecornis (Ralfs) R. Chodat e $S$. ellipticus Corda. No entanto, S. acunae Comas apresenta células externas proporcionalmente mais arqueadas, convexas, S. ecornis (Ralfs) R. Chodat apresenta células mais elípticas e $S$. ellipticus Corda também apresenta células elípticas, mas, com um espessamento na parede celular. São três espécies realmente muito próximas do ponto de vista morfológico, cuja diferenciação entre elas é mais de detalhes, podendo se tornar até bastante difícil sua separação.

Esta foi a única espécie encontrada nos três lagos do PEFI e sempre formando populações com grandes números de espécimes. Quanto ao polimorfismo, S. acunae Comas mostrou variação com relação às dimensões celulares e à convexidade da margem das células externas, que apareceram ora mais ora menos arqueadas.

\section{* Scenedesmus arcuatus (Lemmermann)} Lemmermann var. platydiscus G.M. Smith, Transactions of the Wisconsin Academy of Sciences, Arts \& Letters 18: 451, pl. 30, fig. 101105, 122. 1916.

Figuras 110-111

Cenóbios planos, alternados, com espaços intercelulares muito pequenos, formados por 4-8 células, 1-2 fileiras; células oval-cilindricas, pólos arredondados, células externas levemente côncavas, projetadas às vezes para baixo, às vezes para cima, células externas não totalmente alinhadas, 5,7-8,2 $\times$
1,7-4,2 $\mu \mathrm{m}$; cloroplastidio com ou sem pirenóide. Hábitat: plâncton no Lago das Garças [Sant'Anna et al. 1989: 96, fig. 74-75, como Scenedesmus arcuatus Lemmermann; Sant'Anna et al. 1989: 96, fig. 78, como Scenedesmus bijugus (Turpin) Kützing var. disciformis (R. Chodat) Leite].

Esta variedade difere da típica da espécie pelo fato de suas células estarem arranjadas todas em um mesmo plano. Scenedesmus arcuatus (Lemmermann) Lemmermann var. platydiscus G.M. Smith pode ser facilmente confundida com S. obtusus Meyen, porém, a primeira possui espaços intercelulares menores do que $S$. obtusus Meyen, além do que as células desta última espécie serem mais uniformemente fusiformes, enquanto que as de $S$. arcuatus (Lemmermann) Lemmermann var. platydiscus G.M. Smith têm uma das margens um pouco côncava.

Scenedesmus arcuatus (Lemmermann) Lemmermann var. platydiscus G.M. Smith caracteriza-se por ter os cenóbios curvos, compostos por oito células cujos pólos externos se tocam, isto é, mostram ordenamento costelado. Neste aspecto, a atual variedade difere de $S$. curvatus Bohlin, que também forma cenóbios curvos, mas, cujos pólos celulares externos mantêm-se livres.

Não foi registrada variação morfológica significativa dentro da presente variedade.

* Scenedesmus bicellularis R. Chodat, Preslia 45: 313. 1973.

Figuras 112-113

Cenóbios planos, lineares, formados por 2 células; células elíptico-cilíndricas, margem externa marcadamente convexa, $6,8-7,8 \times 2,1-3,7 \mu \mathrm{m}$; cloroplastidio sem pirenóide.

Hábitat: plâncton no Lago do IAG [Ferragut et al. 2005: 154, fig. 86, como Didymocystis bicellularis (R. Chodat) Komárek].

Podem ocorrer nesta espécie cenóbios formados por 4 células, no entanto, estes são na verdade dois cenóbios de duas células. Scenedesmus bicellularis (R. Chodat) Komárek foi registrada formando grande população, porém, não apresentou variação morfológica significativa.

* Scenedesmus ecornis (Ehrenberg) R. Chodat, Zeitschrif für Hydrologie 3: 170. $1926 \equiv$ 
Scenedesmus quadricaudatus (Turpin) Ehrenberg var. ecornis Ehrenberg ex Ralfs, Annals \& Magazine of Natural History 15: 402, pl. 12: fig. 4c. 1845.

Figura 114

Cenóbios planos, lineares, formados por 2-4 células; células oblongas, pólos arredondados, células externas arqueadas, marcadamente convexas, células internas pouco menos convexas, 3,0-15,5 $\times$ 2,0-8,0 $\mu \mathrm{m}$; cloroplastídio parietal, 1 pirenóide.

Hábitat: plâncton no Lago do IAG [Ferragut et al. 2005: 155, fig. 93, como Scenedesmus ecornis (Ehrenberg) R. Chodat].

Scenedesmus bijugus (Turpin) Kützing é um sinônimo heterotípico de Scenedesmus ecornis (Ehrenberg) R. Chodat e possui células oblongas e cenóbios constituídos por duas até oito células. Os exemplares em Sant'Anna et al. (1989) apresentam somente duas células no cenóbio.

* Scenedesmus ellipticus Corda, Almanach de Carlsbad 5: 208, pl. 4, fig. 48-49. 1835.

Figura 115

Cenóbios planos, lineares, formados por 4 células; células elípticas, pólos arredondados, células externas e internas com espessamento nos pólos, 7,5$8,0 \times$ ca. $2,5 \mu \mathrm{m}$; cloroplastidio parietal, 1 pirenóide. Hábitat: plâncton no Lago do IAG (Ferragut et al. 2005: 155, fig. 95, como Scenedesmus linearis Komárek).

Scenedesmus ellipticus Corda pode ser confundido com Scenedesmus ecornis (Ehrenberg) R. Chodat, contudo, diferem pela forma elíptica da célula e pela ocorrência de espessamento nos pólos celulares da primeira espécie.

O nome S. ecornis (Ehrenberg) R. Chodat tem sido usado com frequência na literatura para identificar esta espécie.

Scenedesmus obtusus Meyen, Verhandlungen der K. Leopoldinisch-carolinischen deutschen Akademie der Naturforscher 14: 775, pl. 43, fig. 30-31. 1829. Figuras 116-119

Cenóbios planos, alternados, formados por 4-8 células, 1-2 séries; células oval-cilíndricas, pólos arredondados, células externas convexas, podendo apresentar uma leve concavidade, células internas mais retas, algumas células do cenóbio podendo apresentar espessamento da parede celular, 5,0-20,3 $\times 2,0-7,4 \mu \mathrm{m}$; cloroplastidio parietal, 1 pirenóide. Hábitat: plâncton no Lago das Garças (SP399781,
SP399782; Sant'Anna et al. 1989: 97, fig. 88, como Scenedesmus ovalternus R. Chodat; Gentil 2000: 55, fig. 13, como Scenedesmus arcuatus Lemmermann), no Lago das Ninféias (SP399783) e no Lago do IAG (Ferragut et al. 2005: 156, fig. 97, como Scenedesmus obtusus Meyen var. obtusus; Ferragut et al. 2005: 156, fig. 98, como Scenedesmus ovalternus R. Chodat).

Scenedesmus obtusus Meyen pode ser facilmente confundido com S. ovalternus R. Chodat var. ovalternus e com Scenedesmus arcuatus Lemmermann var. platydiscus G.M. Smith. Diferem, entretanto, porque S. obtusus Meyen possui espaços intercelulares maiores do que os de $S$. arcuatus (Lemmermann) Lemmermann var. platydiscus G.M. Smith e suas células são relativamente mais fusiformes, enquanto que as de $S$. arcuatus (Lemmermann) Lemmermann var. platydiscus G.M. Smith apresentam margem um pouco côncava.

Foram encontrados representantes de $S$. obtusus Meyen sempre constituindo populações numerosas. Com relação à variação morfológica, deve-se mencionar a ampla variabilidade das dimensões celulares. Além das medidas, deve-se também mencionar a variabilidade com relação à presença de ornamentação na parede celular.

Scenedesmus verrucosus Roll, Russkiî arkhiv protistologii 4: 150. 1925.

Figura 120

Cenóbios planos, lineares, formados por 4-8 células, dispostas em série dupla; células aproximadamente oblongas, 6,5-10,0 × 3,0-9,0 $\mu \mathrm{m}$; parede celular com pequenas verrugas; cloroplastidio parietal, 1 pirenóide.

Hábitat: plâncton no Lago das Garças (SP399781; Sant'Anna et al. 1989: 97, fig. 96-97, como Scenedesmus verrucosus Roll).

Scenedesmus verrucosus Roll pode apresentar cenóbios constituídos por quatro ou oito células, que se distribuem formando duas fileiras. Conforme Sant'Anna (1984), estas células são arranjadas de forma compacta, aparecendo angulares pela compressão mútua. Além disso, possuem parede celular ornada com pequenas verrugas.

Foram encontrados representantes de $S$. verrucosus Roll sempre formando populações com poucos indivíduos. Com relação ao polimorfismo, saliente-se a presença ou ausência de granulação semelhante a verrugas na parede celular. 

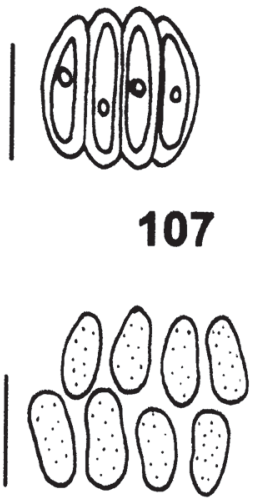

110

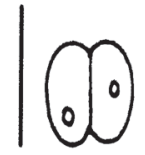

114

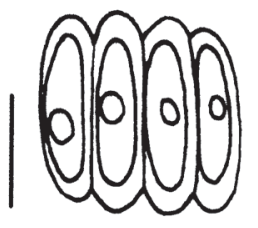

108

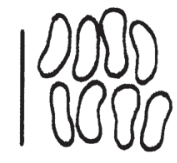

111

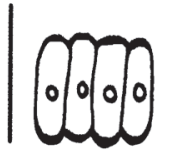

115

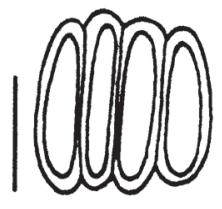

109

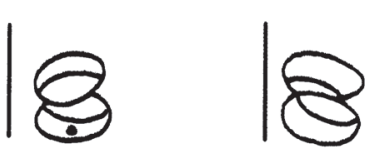

112
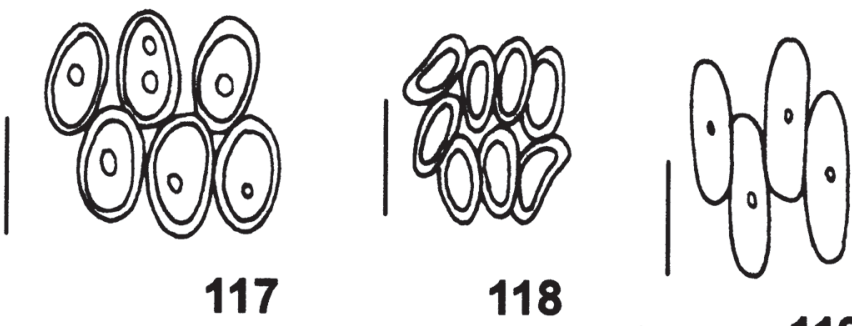

119

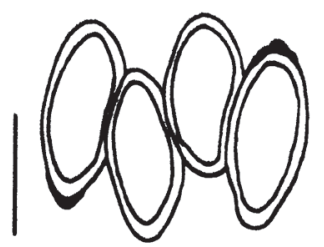

116

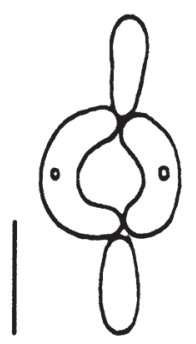

121

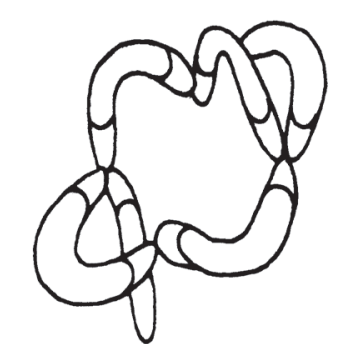

122

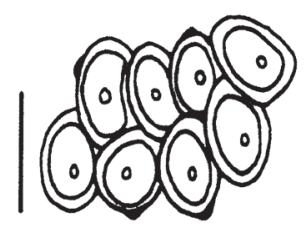

120

Figuras 107-123. Espécies de Scenedesmaceae do Parque Estadual das Fontes do Ipiranga. 107-109. Scenedesmus acunae. 110-111. Scenedesmus arcuatus var. platydiscus. 112-113. Scenedesmus bicellularis. 114. Scenedesmus ecornis (conforme Ferragut et al. 2005). 115. Scenedesmus ellipticus (conforme Ferragut et al. 2005). 116-119. Scenedesmus obtusus. 120. Scenedesmus verrucosus. $121-123$. Tetrallantos lagerheimii. Barras de escala $=10 \mu \mathrm{m}$, exceto quando especificamente indicado.

Figures 107-123. Species of Scenedesmaceae from the "Parque Estadual das Fontes do Ipiranga". 107-109. Scenedesmus acunae. 110-111. Scenedesmus arcuatus var. platydiscus. 112-113. Scenedesmus bicellularis. 114. Scenedesmus ecornis (from Ferragut et al. 2005 ). 115. Scenedesmus ellipticus (from Ferragut et al. 2005). 116-119. Scenedesmus obtusus. 120. Scenedesmus verrucosus. 121-123. Tetrallantos lagerheimii. Scale bars $=10 \mu \mathrm{m}$, except when especifically indicated. 


\section{SUBFAMÍLIA TETRALLANTOIDEAE}

Nesta subfamília aparecem diferentes tipos de cenóbios, em que as células mais ou menos alongadas, elipsóides, lunares, ovadas, cilíndricas, geralmente curvas, estão orientadas espacialmente, mostrando certa polaridade, unidas por um de seus extremos.

\section{Tetrallantos Teiling}

Células em forma de meia-lua, dispostas num grupo de 4 às vezes formando sincenóbios de 8-16 células. Os cenóbios apresentam forma característica: duas células mais ou menos curvas orientadas em paralelo e unidas por seus extremos, geralmente por sua margem côncava, cada uma das células restantes unidas a cada extremo do par anterior. Reprodução vegetativa por autósporos formados em número de 2, 4 ou 8 por célula. Quando os autósporos são liberados constituem um novo cenóbio. Cada célula contém um cloroplastidio parietal, com um pirenóide.

Apenas uma espécie identificada.

Tetrallantos lagerheimii Teiling, Svensk Botanisk Tidskrift 10: 62. 1916.

Figuras 121-123

Cenóbios de 4 células, onde 2 estão no mesmo plano e 2 dispostas verticalmente, tocando seus ápices; células lunadas ou aproximadamente reniformes, 4,2-20,5 × 2,2-6,7 $\mu \mathrm{m}$; cloroplastídio parietal, 1 pirenóide.

Hábitat: plâncton no Lago do IAG (SP399779; Ferragut et al. 2005: 156, fig. 100) e no Lago das Garças (Sant'Anna et al. 1989: 97, fig. 98).

Sant'Anna (1984) mencionou também que a mucilagem cenobial pode ser tão hialina que necessita ser evidenciada utilizando solução aquosa de azul de metileno.

Comparando as populações ora examinadas com a ilustração em Teiling (1916: fig. 62) algumas diferenças morfológicas tornam-se evidentes como, por exemplo, as células serem cilíndricas, levemente arqueadas e, algumas vezes, torcidas no final. Estas características também foram observadas nos materiais coletados em Veracruz no México (Comas et al. 2007) e em Cuba (Comas 1996). Tais diferenças são, todavia, dada seu pouco significado, desprovidas de importância taxonômica.

Tetrallantos lagerheimii Teiling apresentou variação morfológica somente com relação às dimensões celulares, porém, sem qualquer expressão sobre a taxonomia da espécie.

\section{Chave para identificação dos gêneros, espécies e variedades estudados}

1. Cenóbios compostos por pares de células situadas em 1 mesmo plano, alongados em 1 direção, cujo eixo longitudinal passa através dos pares de células (Crucigeniella)

2. Cenóbios com as margens externas das células quase retas ou levemente côncavas C. crucifera

2. Cenóbios com as margens externas das células convexas

3. Células com pirenóide C. apiculata

3. Células sem pirenóide C. rectangularis

1. Cenóbios com 2 células mais ou menos paralelas ou levemente convergentes entre si, as outras 2 células obliquamente unidas às extremidades do par anterior; ou 4 células dispostas em cruz em cenóbios mais ou menos quadrados; ou 4 células dispostas em 1-2 séries paralelas entre si; ou 4 células, sendo 2 orientadas em paralelo e unidas pólo a pólo e as outras 2 unidas a cada extremo do par anterior

4. Cenóbios com 2 células mais ou menos paralelas ou levemente convergentes entre si, as outras 2 células obliquamente unidas às extremidades do par anterior, ou 4 células dispostas em cruz em cenóbios mais ou menos quadrados

5. Cenóbios com 2 células mais ou menos paralelas levemente convergentes entre si ou as outras 2 células obliquamente unidas às extremidades do par anterior (Tetrachlorella) T. alternans

5. Cenóbios mais ou menos em cruz, quadrados ou alargados em 1 direção

6. Cenóbios mais ou menos quadrados, com 1 pequeno espaço no centro; parede celular ornamentada ou não; cenóbios-filhos formando ângulo de $45^{\circ}$ em relação ao cenóbio materno

7. Parede celular ornamentada com grânulos no pólo celular voltado para o exterior do cenóbio

(Pseudotetrastrum) P. punctatum 
8. Cenóbios com margens externas das células mais ou menos retas ou levemente côncavas C. tetrapedia

8. Cenóbios com margens externas das células convexas

9. Parede celular lisa; pirenóide presente

C. quadrata

9. Parede celular ornamentada, com espessamento semelhante a verruga; pirenóide presente ......

C. mucronata

6. Cenóbios geralmente alongados em 1 direção, raramente quadrados; parede celular lisa ou com grânulos, verrugas ou espinhos; cenóbios-filhos orientados no mesmo sentido do cenóbio materno 10. Parede celular lisa; cenóbios-filhos frequentemente unidos por restos das paredes celulares maternas (Westella) W. botryoides

10. Parede celular lisa, com espinhos nas margens externas das células ou com grânulos ou verrugas na superfície

11. Cenóbio formado por células dispostas em 2 pares situados mais ou menos no mesmo nível

(Didymogenes)

12. Células externas com espinhos D. anomala

12. Células externas sem espinhos

D. palatina

11. Sincenóbios transitórios (se formados) que não se unem por restos das paredes maternas

(Tetrastrum)

13. Células com espinhos

14. Células com 1 espinho apenas

T. elegans

14. Células com mais de 1 espinho

T. heteracanthum

13. Células sem espinhos

15. Pirenóide presente

T. triangulare

15. Pirenóide ausente

T. komarekii

4. Cenóbios com 4 células dispostas em cruz em cenóbios mais ou menos quadrados; ou 4 células dispostas em 1-2 séries paralelas entre si; ou 4 células dispostas \pm em cruz, sendo 2 cordiformes e 2 oblongo-cilíndricas; ou 4 células, sendo 2 orientadas em paralelo e unidas pólo a pólo e as outras 2 unidas a cada extremo do par anterior

16. Cenóbios com 4 células, sendo 2 orientadas em paralelo e unidas pólo a pólo e as outras 2 unidas a cada extremo do par anterior

(Tetrallantos) T. lagerheimii

16. Cenóbios com 4 células dispostas \pm em cruz, sendo 2 cordiformes e 2 oblongo-cilíndricas; ou com 4 células dispostas em cruz em cenóbios mais ou menos quadrados

17. Cenóbios com 4 células dispostas \pm em cruz, sendo 2 cordiformes e 2 oblongo-cilíndricas

(Dinorphococcus) D. lunatus

17. Cenóbios com 4 células dispostas em cruz em cenóbios mais ou menos quadrados

18. Espinhos presentes em algumas ou em todas do cenóbio

19. Cenóbios planos formados por 2-16 células dispostas linear ou alternadamente, formando 1 linha cujas células podem estar dispostas em 1-2 séries; parede celular ornamentada com verrugas, espinhos, dentículos ou rosetas (Desmodesmus)

20. Cenóbios com células dispostas em 2 séries (alternados)

21. Um espinho longo em cada pólo das células externas do cenóbio

21. Um a três espinhos curtos em cada pólo das células externas do cenóbio

D. denticulatus var. denticulatus

20. Cenóbios com células dispostas em 1 série (lineares)

22. Um a dois espinhos longos na margem livre das células externas do cenóbio

23. Espinhos marginais das células externas do cenóbio inseridos juntos (aos pares)

D. flavescens var. breviarticulatus

23. Espinhos marginais das células externas do cenóbio inseridos isoladamente (não aos pares)

24. Células intermediárias do cenóbio com 1 espinho longo em cada pólo 
D. pleiomorphus

24. Células intermediárias do cenóbio sem espinhos polares

25. Espinhos de tamanho praticamente iguais entre si ....

D. spinosus

25. Espinhos de tamanhos diferentes entre si: os marginais das células externas maiores que os polares D. abundans

22. Um a inúmeros espinhos curtos ou uma estrutura igual a um pente na margem livre das células externas do cenóbio

26. Espinhos apenas nos pólos das células externas do cenóbio

27. Um a dois espinhos na margem livre das células externas do cenóbio

27. Inúmeros espinhos curtos ou estrutura semelhante a um pente na margem livre das células externas do cenóbio.

28. Células externas do cenóbio oblongas D. armatus var. spinosus p.p.

28. Células externas do cenóbio elípticas D. spinulatus

29. Espinhos curtos na margem livre das células externas do cenóbio

30. Dois a três espinhos nos pólos das células externas e intermediárias do cenóbio D. pseudodenticulatus p.p.

30. Um a dois espinhos nos pólos das células externas e 1 nos pólos das células intermediárias do cenóbio

31. Células oblongas D. pseudodenticulatus p.p.

31. Células elípticas D. serratus p.p.

29. Estrutura semelhante a um pente na margem livre das células externas do cenóbio

32. Células externas do cenóbio sem espinhos D. brasiliensis

32. Células externas do cenóbio com 1-2 espinhos

33. Células externas do cenóbio com 1 espinho em um dos pólos, o outro pólo sem espinho

34. Um espinho em cada pólo das células intermediárias do cenóbio

D. armatus var. bicaudatus

34. Sem espinhos polares nas células intermediárias (quando presentes, costelas longitudinais presentes) D. intermedius var. acutispinus

33. Células externas do cenóbio com 1 espinho em cada pólo

35. Células elípticas a elíptico-fusiformes D. serratus p.p.

35. Células ovadas a oblongas 36. Células com 1 espinho curto em cada pólo D. armatus var. spinosus p.p. D. denticulatus var. linearis

36. Células com 1 espinho longo em cada pólo

37. Costelas e pequenos dentículos presentes nas células internas

38. Células com costelas D. armatus var. armatus

38. Células sem costelas D. opoliensis var. carinatus

37. Costelas e pequenos dentículos ausentes nas células internas

26. Espinhos nos pólos das células externas do cenóbio e também das intermediárias

39. Células com espinhos de tamanhos diferentes nos pólos D. dispar

39. Células com espinhos de tamanhos mais ou menos iguais nos pólos

40. Células com espinhos localizados excentricamente

41. Células em contato apenas subapical D. opoliensis var. opoliensis

41. Células todas em contato D. opoliensis var. mononensis

40. Células com espinhos localizados em pólos proeminentes

42. Células com espinhos localizados em pólos proeminentes D. protuberans

42. Células muito grandes, atingindo quase $28 \mu \mathrm{m}$ compr.

43. Células com 13,6-27,8 $\mu \mathrm{m}$ compr., 4,6-8,9 $\mu \mathrm{m}$ larg. 43. Células com 6,1-22,7 $\mu \mathrm{m}$ compr., 1,7-8,7 $\mu \mathrm{m}$ larg. D. maximus D. communis

19. Cenóbios formados apenas por 2 células dispostas uma ao lado da outra segundo seus eixos 
mais longos; parede celular ornamentada com material inorgânico granular ou verrugas

(Pseudodidymocystis)

44. Parede celular lisa P. fina

44. Parede celular ornamentada

P. planctonica

18. Espinhos ausentes em todas as células do cenóbio

45. Células fusiformes ou elíptico-fusiformes, com os pólos mais ou menos agudos

.. (Scenedesmus, subgênero Acutodesmus)

46. Cenóbios 2-celulados; células elípticas e elíptico-cilíndricas

S. bicellularis

46. Cenóbios 4-celulados; células de outras formas

47. Células dispostas alternando uma mais para cima outra mais para baixo

48. Células oblongas a oblongo-cilíndricas S. ecornis

48. Células elíptica a elíptico-cilíndricas

49. Células com espessamento nos pólos

S. acunae

49. Células sem espessamento nos pólos

S. ellipticus

47. Células dispostas sem alternar uma mais para cima e outra mais para baixo

50. Parede celular com verrugas, principalmente, nos pólos

S. verrucosus

50. Parede celular sem verrugas

51. Células com espaços intercelulares

S. arcuatus var. platydiscus

51. Células sem espaços intercelulares

S. obtusus p.p.

45. Células com os pólos arredondados e destituídos de espinhos

(Scenedesmus, subgênero Scenedesmus)

52. Cenóbios com células dispostas em 1 série (lineares)

53. Pólos celulares pontiagudos

S. regularis

53. Pólos celulares acuminados

54. Pólos celulares afilados gradualmente para a extremidade

54. Pólos celulares afilados abruptamente para a extremidade

S. acuminatus var. acuminatus p.p.

S. obliquus var. dimorphus p.p.

52. Cenóbios com células dispostas em 2 séries (alternados)

55. Células arranjadas em mais de 1 plano do espaço

S. acuminatus var. elongatus

55. Células arranjadas em 1 só plano do espaço

56. Pólos celulares capitados S. indicus

56. Pólos celulares não capitados

57. Pólos celulares acuminados S. acuminatus var. acuminatus p.p.

57. Pólos celulares pontiagudos

58. Células fusiformes retas

S. obliquus var. dimorphus p.p.

58. Células fusiformes curvadas

59. Comprimento da célula 23,7-29,1 $\mu \mathrm{m}$, largura 3,6-4 $\mu \mathrm{m}$

59. Comprimento da célula 39,0-50,0 $\mu \mathrm{m}$, largura 7,0-8,0 $\mu \mathrm{m}$

S. javanensis var. javanensis

S. javanensis var. schroeteri

A família Scenedesmaceae é uma das melhor representadas no Parque Estadual das Fontes do Ipiranga. Seu levantamento levou a algumas ponderações interessantes como, por exemplo, sua riqueza total de espécies representada por 55 táxons infragenéricos representados por 47 espécies e 11 variedades que não são as típicas de suas respectivas espécies. O Lago das Garças foi o ambiente que apresentou o maior número de táxons (45), seguido pelo Lago do IAG (27) e pelo Lago das Ninféias (11). Dos 45 táxons que ocorreram no Lago das Garças, 25 foram exclusivos desse ambiente; dos 27 táxons do Lago do IAG, seis foram exclusivos; e dos 11 do Lago das Ninféias, 3 foram exclusivos. Chama atenção nessas cifras a aparente contestação da teoria que afirma que os ambientes eutróficos 
e hipertróficos comportam poucas espécies, ao contrário dos ambientes oligotróficos, que incluiriam um número comparativamente maior de espécies. O Lago das Garças é um ambiente hipertrófico e deveria, por isso, apresentar a menor riqueza de espécies dos três ambientes estudados. Entretanto, no presente caso, o referido lago apresentou-se ca. $67 \%$ mais rico se comparado com o Lago do IAG, um ambiente oligotrófico e 309\% mais rico se comparado com o Lago das Ninféias, um ambiente mesotrófico. Tais resultados são obviamente falsos e devidos, na prática, simplesmente ao maior esforço de coleta efetuado no Lago das Garças e representado por um número muito maior de trabalhos realizados nesse sistema quando comparado com os demais.

\section{Literatura citada}

Ahlstrom, E.H. \& Tiffany, L.H. 1934. The algal genus Tetrastrum. American Journal of Botany 21: 499-507.

An, S.S., Friedl, T. \& Hegewald, E. 1999. Phylogenetic relationships of Scenedesmus and Scenedesmus-like coccoid green algae as referred from ITS-2 rDNA sequence comparisons. Plantbiology 1: 418-428.

Barcelos, E.M. 2003. Avaliação do perifíton como sensor da oligotrofização experimental em reservatório eutrófico (Lago das Garças, São Paulo). Dissertação de Mestrado, Universidade Estadual Paulista, Rio Claro.

Belkinova, D. \& Mladenov, R. 2000. Veränderlichkeit der Zellmorphologie bei einigen Scenedesmus-Arten der Untergattung Acutodesmus (Chlorophyta, Chlorococcales). Algological Studies 96: 79-88.

Belkinova, D. \& Mladenov, R. 2002. Morphologische Veränderlichkeit bei klonalen Culturen von Scenedesmus nygaardii Hub.Pest. und Scenedesmus bernardii G.M. Smith (Chlorophyta). Algological Studies 104: 123138.

Bicudo, C.E.M. \& Bicudo, R.M.T. 1967. Floating communities of algae in an artificial pond in the parque do estado, SP, Brazil. Journal of Phycology 3: 233-234.

Bicudo, C.E.M., Bicudo, D.C., Castro, A.A.J. \& Picelli-Vicentim, M.M. 1992. Fitoplâncton do trecho a represar do Rio Paranapanema (Usina Hidrelétrica de Rosana), Estado de São Paulo, Brasil. Revista Brasileira de Biologia 52: 293-310.
Bicudo, C.E.M. \& Menezes, M. 2006. Gêneros de algas de águas continentais do Brasil: chave para identificação e descrições. RiMa Editora, São Carlos.

Bicudo, C.E.M., Ramírez R., J.J., Tucci, A. \& Bicudo, D.C. 1999. Dinâmica de populações fitoplanctônicas em ambiente eutrofizado: o Lago das Garças, São Paulo. In: R. Henry (ed.). Ecologia de reservatórios: estrutura, função e aspectos sociais. FUNDBIO/FAPESP, Botucatu, pp. 449-508.

Biesemeyer, K.F. 2005. Variação nictemeral da estrutura e dinâmica da comunidade fitoplanctônica em função da temperatura da água nas épocas de seca e chuva em reservatório urbano raso mesotrófico (Lago das Ninféias), Parque Estadual das Fontes do Ipiranga. Dissertação de Mestrado, Instituto de Botânica, São Paulo.

Bourrelly, P. 1990. Les algues d'eau douce: initiation à la systématique, 1: les algues vertes. v. 1 . Éditions N. Boubée \& Cie. Paris.

Chodat, R. 1926. Scenedesmus: étude de génétique, de systématique expérimentale et d'hydrobiologie. Zeitschrif für Hydrologie 3: 71-258.

Comas, A. 1984. Chlorococcales (Chlorophyceae) de algunos acuatorios de Pinar del Rio, Cuba. Acta Botanica Cubana 17: 1-60.

Comas, A. 1996. Las Chlorococcales dulciacuícolas de Cuba. Biblioteca Phycologica 99: 1-265.

Comas, A. \& Komárek, J. 1984. Taxonomy and nomenclature of several species of Scenedesmus (Chlorellales). Algological Studies 35: 135-157.

Comas, A., Novelo, E. \& Tavera, R. 2007. Coccal green algae (Chlorophyta) in shallow ponds in Veracruz,México.Algological Studies 124:29-69.

Crossetti, L.O. 2002. Efeitos do empobrecimento experimental de nutrientes sobre a comunidade fitoplanctônica em reservatório eutrófico raso, Lago das Garças, São Paulo. Dissertação de Mestrado, Universidade de São Paulo, Ribeirão Preto.

Ferragut, C., Lopes, M.R.M., Bicudo, D.C., Bicudo, C.E.M. \& Vercellino, I.S. 2005. Ficoflórula perifítica e planctônica (exceto Bacillariophyceae) de um reservatório oligotrófico raso (Lago do IAG, São Paulo). Hoehnea 32: 137-184.

Fermino, F.S. 2006. Avaliação sazonal dos efeitos do enriquecimento por $\mathrm{N}$ e $\mathrm{P}$ sobre o perifíton em represa tropical rasa mesotrófica (Lago 
das Ninféias, São Paulo). Tese de Doutorado, Universidade Estadual Paulista, Rio Claro.

Fonseca, B.M. 2005. Diversidade fitoplanctônica como discriminador ambiental em dois reservatórios rasos com diferentes estados tróficos no Parque Estadual das Fontes do Ipiranga. Tese de Doutorado, Universidade de São Paulo, São Paulo.

Gentil, R.C. 2000. Variação sazonal do fitoplâncton de um lago subtropical eutrófico e aspectos sanitários, São Paulo, SP. Dissertação de Mestrado, Universidade de São Paulo, São Paulo.

Hegewald, E. 1978. Eine neue Unterteilung der Gattung Scenedesmus Meyen. Nova Hedwigia 29: 343-376.

Hegewald, E. 1979. Vergleichende Beobachtungen an Herbarmaterial und Freilandmaterial von Scenedesmus. Algological Studies 24: 264-286.

Hegewald, E. 1989. The Scenedesmus strains of the Culture Collection of the University of Texas at Austin (UTEX). Algological Studies 55: 153-189.

Hegewald, E. 2000. New combinations in the genus Desmodesmus (Chlorophyceae, Scenedesmaceae). Algological Studies 96: 1-18.

Hegewald, E., An, S.S. \& Tsarenko, P. 1998. Revision of Scenedesmus intermedius Chod. (Chlorophyta, Chlorococcales). Algological Studies 88: 67-104.

Hegewald, E. \& Deason, T.R. 1989. Pseudodidymocystis, a new genus of Scenedesmaceae (Chlorophyceae). Algological Studies 55: 119-127.

Hegewald, E., Engelberg, K.E. \& Paschma, R. 1988. Beitrag zur Taxonomie der Gattung Scenedesmus, Subgenus Scenedesmus (Chlorophyceae). Nova Hedwigia 47: 497-533.

Hegewald, E. \& Hanagata, N. 2000. Phylogenetic studies on Scenedesmaceae (Chlorophyta). Algological Studies 100: 29-49.

Hegewald, E. \& Silva, P. 1988. Annotated catalogue of Scenedesmus and nomenclaturally related genera, including original descriptions and figures. Bibliotheca Phycologica 80: 1-587.

Hegewald, E. \& Wolf, M. 2003. Phylogenetic relationships of Scenedesmus and Acutodesmus (Chlorophyta, Chlorophyceae) as inferred from 18S rDNA and ITS-2 sequence comparisons. Plant Systematics and Evolution 241: 185-191.

Heynig, H. 1989. Interessante Phytoplankter aus Gewässern des Bezirks Halle (DDR), 6. Archiv für Protistenkunde 137: 57-68.
Heynig, H. \& Krienitz, L. 1987. Interessante coccale Grünalgen (Chlorellales) aus einem Altwasser der Elbe (DDR). Archiv für Protistenkunde 134: 49-58.

Hindák, F. 1974. The chlorococcal algal genus Didymogenes Schmidle 1905. Biológia 29: 559570.

Hindák, F. 1977. Studies on the chlorococcal algae (Chlorophyceae), 1. Biologické Prace 23: 1-190.

Hindák, F. 1990. Studies on the chlorococcal algae (Chlorophyceae), 5. Biologické Prace 36: 1-225.

Holtmann, T. \& Hegewald, E. 1986. Der Einflu $\beta$ von Nährlösungen auf die Variabilität von Isolaten der Gattung Scenedesmus Untergattung Acutodesmus. Algological Studies 44: 365-380.

Hortobágyi, T. 1967. Neue Beiträge zur Kenntnis der Scenedesmus ungars. Acta Botanica Hungarica 13: 21-59.

Komárek, J. 1974. Taxonomische Bemerkungen zu einigen Arten der Mikroflora der Teiche in Böhmen. Acta Scientiarum Naturalium Musei Bohemici Meridionalis České Budejovice 14: 161-190.

Komárek, J. 1983. Contribuition to the chlorococcal algae of Cuba. Nova Hedwigia 37: 65-180.

Komárek, J. \& Fott, B. 1983. Chlorophyceae (grünalgen) Ordnung: Chlorococcales.In:HuberG. Pestalozzi (org.). Das Phytoplankton des Süsswassers: Systematic und Biologie. v. 7(1). E. Schweizerbart'sche Verlagsbuchhandling (Nägele u. Obermiller), Stuttgart.

Krienitz, L. 1987. Studien zur Morphologie und Taxonomie der Untergattung Acutodesmus (Chlorellales). Algological Studies 46: 1-37.

Leite, C.R. 1974. Contribuição ao conhecimento das Chlorococcales (Chlorophyceae) planctônicas do Parque Estadual das Fontes do Ipiranga, São Paulo, Brasil. Dissertação de Mestrado, Universidade de São Paulo, São Paulo.

Leite, C.R. 1979. Chlorococcales (Chlorophyceae) do Estado de São Paulo Brasil. Dissertação de Doutorado, Universidade de São Paulo, São Paulo.

Lopes, M.R.M. 1999. Eventos perturbatórios que afetam a biomassa, a composição e a diversidade de espécies do fitoplâncton em um lago tropical oligotrófico raso (Lago do Instituto Astronômico e Geofísico, São Paulo, SP). Tese de Doutorado, Universidade de São Paulo, São Paulo.

Mladenov, R. \& Furnadžieva, S. 1999. Morphologische Veränderlichkeit klonaler 
Culturen von Scenedesmus falcatus Chod. und Scenedesmus acuminatus (Lagerh.) Chod. Algological Studies 79: 93-107.

Moura, A.T. 1996. Estrutura e dinâmica da comunidade fitoplanctônica numa lagoa eutrófica, São Paulo, SP, Brasil, a curtos intervalos de tempo: comparação entre épocas de chuva e seca. Dissertação de Mestrado, Universidade Estadual Paulista, Rio Claro.

Nogueira, I.S. 1991. Chlorococcales sensu latu (Chlorophyceae) do Município de Rio de Janeiro e arredores: inventário e considerações taxonômicas. Tese de Doutorado, Universidade de São Paulo, São Paulo.

Ooshima, K. 1981. Taxonomic studies on Scenedesmus in Japan, 1: on Scenedesmus acuminatus (Lag.) Chod. and its varieties and $S$. javanensis Chod. Japanese Journal of Phycology 29: 85-93.

Philipose, M.T. 1967. Chlorococcales. Indian Council of Agricultural Research, New Delhi.

Picelli-Vicentim, M.M. 1987. Chlorococcales planctônicas do Parque Regional do Iguaçu, Curitiba, Estado do Paraná. Revista Brasileira de Biologia 47: 57-85.

Ramírez R., J.J. 1996. Variações espacial vertical e nictemeral da estrutura da comunidade fitoplanctônica e variáveis ambientais em quatro dias de amostragem de diferentesépocas do anono Lago das Garças, São Paulo. Tese de Doutorado, Universidade de São Paulo, São Paulo.

Sant'Anna, C.L. 1984 Chlorococcales (Chlorophyta) do Estado de São Paulo, Brasil. J. Cramer, Vaduz.

Sant'Anna, C.L., Azevedo, M.T.P. \& Sormus, L. 1989. Fitoplâncton do Lago das Garças, Parque Estadual das Fontes do Ipiranga, São Paulo, SP, Brasil: estudo taxonômico e aspectos ecológicos. Hoehnea 16: 89-131.

Schetty, S.P. 1998. Contribuição a ficoflórula planctônica (exceto diatomáceas) do Lago das Ninféias, PEFI, São Paulo. Monografia de
Conclusão de Curso, Universidade Presbiteriana Mackenzie, São Paulo.

Silva, L.H.S. 1999. Fitoplâncton de um reservatório eutrófico (Lago Monte Alegre). Revista Brasileira de Biologia 59: 281-303.

Smith, G.M. 1916. A monograph of the algal genus Scenedesmus based upon culture studies. Transactions of the Wisconsin Academy of Sciences, Arts and Letters 18: 422-530.

Teiling, E. 1916. Tetrallantos, eine neue Gattung der Protococcoideen. Svensk botaniska Tidskrift 10: 59-65.

Toledo, L. \& Comas, A. 1988. Sobre la variabilidad morfológica y la taxonomia de algunas espécies de Scenedesmus (Chlorellales). Acta Botanica Cubana 57: 1-32.

Tsarenko, P.M. \& Petlevanny, O.A. 2001. Doplolneniek "Raznoobraziju vodoroslej Ukrainy. Algologia, Suppl.: 1-130.

Tucci, A. 2002. Sucessão da comunidade fitoplanctônica de um reservatório urbano e eutrófico, São Paulo, SP, Brasil. Tese de Doutorado, Universidade Estadual Paulista, Rio Claro.

Tucci, A., Sant'Anna, C.L., Gentil, R.C. \& Azevedo, M.T.P. 2006. Fitoplâncton do Lago das Garças, São Paulo, Brasil: um reservatório urbano eutrófico. Hoehnea 33:147-175.

Uherkovich, G. 1966. Die Scenedesmus-Arten Ungarns. Akademiai Kiadó, Budapest.

Van-den-Hoek, C., Mann, D.G. \& Jahns, H.M. 1997. Algae: an introduction to phycology. Cambridge University Press, Cambridge.

Vercellino, I.S. 2001. Sucessão da comunidade de algas perifíticas em dois reservatórios do Parque Estadual das Fontes do Ipiranga, São Paulo: influência do estado trófico e período climatológico. Dissertação de Mestrado, Universidade Estadual Paulista, Rio Claro.

West, W. \& West, G.S. 1902. A contribuition to the freshwater algae of Ceylon. Transactions of the Linnean Society of London, série Botânica 6: 123-215. 